Karel A.C. De Schamphelaere $\quad$ ORCID iD: 0000-0002-5063-922X

\title{
The effects of nickel on the structure and functioning of a freshwater plankton community under high dissolved organic carbon conditions: a microcosm experiment
}

\author{
Charlotte Nys* $^{\mathrm{a}, \mathrm{b}}$, Tina Van Regenmortel ${ }^{\mathrm{a}}$, Karel De Schamphelaere ${ }^{\mathrm{a}}$ \\ ${ }^{a}$ GhenToxLab, Department of Animal Science and Aquatic Ecology, Ghent University, \\ Ghent, Belgium \\ ${ }^{\mathrm{b}}$ ARCHE Consulting, Ghent (Wondelgem), Belgium \\ Running head: Effects of Ni on plankton community structure and function
}

Corresponding author: Charlotte Nys (charlotte.nys@arche-consulting.be)

Keywords: phytoplankton; zooplankton; community; bioavailability; risk assessment; metal

Address correspondence to charlotte.nys@arche-consulting.be

\section{ABSTRACT}

In the present study, we aimed to test the protectiveness of the bioavailabilitynormalisation procedure, with its associated hazardous concentrations for $\mathrm{x} \%$ of the species (HCx), that is currently implemented to derive environmental threshold concentrations for Ni in European environmental legislative frameworks. We exposed a natural plankton-dominated community to three constant Ni concentrations, i.e. a control

This article has been accepted for publication and undergone full peer review but has not been through the copyediting, typesetting, pagination and proofreading process, which may lead to differences between this version and the Version of Record. Please cite this article as doi: 10.1002/etc.4504.

This article is protected by copyright. All rights reserved. 
with no Ni added (background $\mathrm{Ni}$ between 1.2 and $4 \mu \mathrm{g} / \mathrm{L}$ ) and the bioavailabilitynormalized HC5 and HC50 of 24 and $97 \mu$ g dissolved Ni/L, respectively, during a 56dmicrocosm experiment under high DOC conditions (dissolved organic carbon $14 \mathrm{mg} / \mathrm{L}$ at test initiation). The effects of the bioavailability-normalised HC5 and HC50 were evaluated at the level of the community structure (community composition and plankton group abundances), community functioning (measured as indirect physicochemical proxies for overnight respiration and carbon fluxes) and individual species abundances. The bioavailability-normalised HC50-treatment had clear effects (defined as effects occurring on at least two consecutive sampling days) on both the structure and functioning of the investigated aquatic community. Through its effect on community functioning (i.e. reduced $\mathrm{pH}$ and DOC), Ni also influenced its own bioavailability. Clear direct effects of $\mathrm{Ni}$ were observed for only three species (i.e. the cyanobacteria Oscillatoria sp. 1 and the rotifers 'Asplanchna/Testidunela sp' and 'Trichocerca group similis'). Most other effects occurring in the plankton community in the HC50 treatment were indirect and likely driven by the direct effect of $\mathrm{Ni}$ on the cyanobacteria Oscillatoria sp. 1, which was the dominant phytoplankton species in the control microcosms. In contrast to this, the bioavailability-normalised HC5 did not induce clear effects on community structure and functioning endpoints, as these were only affected on individual sampling days. Clear (direct) effects were observed for only two plankton species (i.e. the rotifer Trichocerca group similis and the cyanobacteria Oscillatoria sp. 1), but their abundances recovered to control levels at the end of the study. In addition, a few species (1 phytoplankton and 3 zooplankton species) were affected in the HC5 treatment only on the last sampling day. It is uncertain whether or not these species would have shown clear

This article is protected by copyright. All rights reserved. 
effects over a longer exposure duration. Thus, our study shows that the bioavailabilitynormalised HC5 of Ni at high DOC induced clear effects on a few individual species. However, the overall conclusion is that the bioavailability-normalised HC5 of $\mathrm{Ni}$ as derived with the procedure that is currently implemented in European legislative frameworks protects against clear effects on community structure and function.

Keywords: metal toxicity, ecological risk assessment, freshwater toxicology, biotic ligand model, microcosm, plankton community

Address correspondence to charlotte.nys@arche-consulting.be

\section{INTRODUCTION}

Nickel (Ni) is listed as one of the priority substances under the European Water Framework Directive (WFD) (EC 2013). Hence, a European Union (EU) wide environmental quality standard (EQS) for Ni in the aquatic environment has been adopted. The importance of taking into account Ni bioavailability (Deleebeeck et al. 2007, 2008, 2009) has been recognized within the WFD, and, therefore, the current European Ni EQS allows a bioavailability-correction to the water chemistry of the receiving water (EC 2013). In addition, the derivation of the Predicted No-Effect Concentrations (PNEC) within the European risk assessment procedures for metals under the Registration, Evaluation, Authorization and Restriction of Chemicals-directive (REACH) is also preferentially based on bioavailability normalizations (ECHA 2008). In practice, the bioavailable EQS and PNEC for Ni are derived using a large dataset containing chronic Ni toxicity data (mostly $10 \%$ effect concentrations) obtained in standard single species ecotoxicity tests. This toxicity dataset is normalized to a specific target water chemistry using the chronic Ni bioavailability models developed for

This article is protected by copyright. All rights reserved. 
invertebrates (D. magna, C. dubia), fish and algae (Deleebeeck et al. 2007, 2008, 2009). An environmental threshold concentration, such as the $5 \%$ hazardous concentration (HC5), is then derived from the species-sensitivity distribution (SSD) combining the bioavailability normalized toxicity data, as explained in detail in Schlekat et al. (2010) and Nys et al. (2016).

The underlying assumption of this approach is that the bioavailability-based EQS or PNEC is protective for the effects of $\mathrm{Ni}$ on natural aquatic communities (Posthuma et al. 2000). Because the effects of chemicals in actual field communities are difficult to unravel, the validity of this assumption is often evaluated using microcosm or mesocosm experiments (Del Signore et al. 2016). This type of experiments uses controlled exposure concentrations to address the direct effects of toxicants on the population and community level, as well as possible indirect effects, which may occur because of changes in competition and predation interactions (Rorh and Crumrine 2005). Recently, Hommen et al. (2016) investigated the effects of $\mathrm{Ni}$ on a freshwater community in a water with high Ni bioavailability (high $\mathrm{pH}$, low to medium DOC). They concluded that the bioavailability-normalization approach currently used for $\mathrm{Ni}$ was protective for community-level effects, because the No-Observed-Adverse-Effect Concentration (NOAEC) of the most sensitive taxon, snails, was at least two times higher than the bioavailability-normalized HC5 of the specific test system. In addition, exposures to Ni concentrations that were up to 4-times higher than the bioavailability-normalized HC5 did not affect the phytoplankton or the zooplankton community (Hommen et al. 2016). The test system of Hommen et al. (2016) represented a rather high Ni bioavailability situation (i.e. high pH and low to medium Dissolved Organic Carbon [DOC]: median pH 
of 8.6 and median DOC concentration of $3.9 \mathrm{mg} / \mathrm{L}$ ), in which the median bioavailabilitynormalized HC5 of $5.5 \mu$ g dissolved $\mathrm{Ni} / \mathrm{L}$ was relatively close to the baseline conditions used to derive the bioavailable-EQS implemented under the WFD (i.e. $4 \mu \mathrm{g}$ dissolved $\mathrm{Ni} / \mathrm{L}$; EC 2013). Given the wide range of physico-chemistry in European waters, it is important to evaluate whether the bioavailability normalization procedure for $\mathrm{Ni}$ and its associated environmental threshold (HC5) that were developed with single-species bioavailability models (Nys et al. 2016) are also protective for complex communities under different bioavailability conditions.

Chemical stressors may also affect important community functions, such as oxygen dynamics, nutrient turnover rates and decomposition rates through their direct or indirect effects on key taxa (Fleeger et al. 2003, Johnston et al. 2014, Artigas et al. 2014). Within the environmental legislation, it is assumed that the protection of community structure also preserves community functioning (EC 2003), although this assumption has hardly been addressed in community studies with metals (but see Roussel et al. (2008), Van de Perre et al. (2016) and Van Regenmortel et al. (2018) for three exceptions).

Here, we aimed to evaluate the protectiveness of the bioavailability-normalization approach under conditions of high DOC (as opposed to the low to medium DOC condition in Hommen et al., 2016). To address this research objective, we exposed a natural plankton-dominated community to two constant Ni concentrations (bioavailable HC5 and HC50) and a control during a 56d-microcosm experiment. More specifically, we derived No-Observed Effect Concentrations (NOEC) for Ni for the plankton community structure, community functioning and individual species. We hypothesized that no clear effects (defined as significant effects occurring on at least two consecutive 
days) on community functioning and structure would be observed at the HC5, but that relatively strong effects would occur at the HC50.

\section{MATERIALS AND METHODS}

\section{Experimental design}

To investigate the community-level effects of $\mathrm{Ni}$, a microcosm experiment was conducted that lasted 8 weeks. The effects of $\mathrm{Ni}$ on a plankton community were evaluated using the following treatments: a control treatment (no metals added), a HC5 treatment and a HC50 treatment (=3 treatments in total). The microcosms evaluated in the present study were part of a larger microcosm study to answer in a resource-efficient manner a broad array of research questions with in total 15 individual treatments (metal mixture treatments were published in Van Regenmortel et al. 2018). Hence, including more Ni treatments was not feasible. However, this design and its associated dataanalysis (see further) is still adequate to evaluate the protectiveness of the HC5. A similar design has previously been used to evaluate the protectiveness of the Zn HC5 (Van de Perre et al. 2015). The control treatment received 4 replicates, all other treatments received 3 replicates, which gave a total of 10 cosms. Microcosm exposures were performed in polystyrene aquaria of $10 \mathrm{~L}$ (31x18x16 LxWxH; Flamingo). The aquaria contained a sediment layer of approximately $2 \mathrm{~cm}$ and $5 \mathrm{~L}$ natural water, both collected from an uncontaminated mesotrophic pond (Sinderhoeve Experimental Station, Renkum, The Netherlands) in September 2015. The microcosms were randomly positioned in a water bath $\left(16-18^{\circ} \mathrm{C}\right.$, representing the average local temperature in late spring/early summer of this particular ecosystem) under a 12:12 hours light:dark cycle (55 $\mu \mathrm{mol} . \mathrm{m}^{-2} . \mathrm{s}^{-}$ 
$\left.{ }^{1}\right)$.The microcosms were seeded with zooplankton collected from uncontaminated small water bodies at the Sinderhoeve experimental site. Three small snails $(<1 \mathrm{~cm})$ (Lymnaea stagnalis) were added to every cosm to prevent growth of periphyton. A pre-treatment period of 4 weeks was run prior to the actual start of the experiment. During this period (and also during the experiment), nutrients $\left(\mathrm{NH}_{4} \mathrm{NO}_{3}, 1 \mathrm{mg} \mathrm{N} / \mathrm{L}\right.$ and $\mathrm{KH}_{2} \mathrm{PO}_{4} 0.01 \mathrm{mg}$ $\mathrm{P} / \mathrm{L}$ ) were added twice a week to stimulate phytoplankton growth. In the pre-treatment period, the water from all the microcosms was mixed once a week to guarantee similar start conditions in all test systems (Brock et al. 2014; Van de Perre et al. 2016). A detailed description of the experimental setup can be found in Van Regenmortel et al. (2018).

The HC5 and HC50 concentrations to be applied to the microcosms were calculated by normalizing chronic toxicity data with chronic bioavailability models using the bioavailability normalization tool of Nys et al. (2016). Normalizations were executed based on the average measured water chemistry variables of all microcosms the day before the start of the experiment (Table 1). A log-normal SSD was fitted to the BLMnormalized chronic Ni toxicity data (Nys et al. 2016), from which the HC5 and HC50 were derived. This is in accordance with the procedure used in the European risk assessment for Ni (DEPA 2008). The corresponding calculated HC5 and HC50 were 24 and $97 \mu$ g dissolved $\mathrm{Ni} / \mathrm{L}$, respectively.

\section{Metal addition and chemical analyses}

Ni was added to the microcosm by distributing the correct volume of stock solution (12.0 $\mathrm{mL}$ and $50.5 \mathrm{~mL}$ for the HC5 and HC50 treatment of a $9.6 \mathrm{mg} \mathrm{Ni} / \mathrm{L}$ stock solution, respectively) evenly over the water surface of the microcosms at test initiation. The 
spiked metal was stirred into the water as a result of the compressed air flow above the water column (see Van Regenmortel et al. 2018). Ni concentrations were adjusted daily by additional spiking to compensate for losses from the water column. Ni was always added at a concentration 15\% above the nominal concentrations in order to maintain an average Ni concentration equal to the nominal concentration. The required volume of stock solution to achieve this concentration was calculated based on the last available $\mathrm{Ni}$ measurement. Samples for dissolved metals were taken twice a day to monitor the metal concentrations. Samples were taken just before the spiking of $\mathrm{Ni}$ and between $15 \mathrm{~min}$ and 35 min after spiking. Sampling consisted of taking a $10 \mathrm{~mL}$ filtered sample (filtered through a $0.45 \mu \mathrm{m}$ filter; Acrodisc, PALL Life Sciences; after preconditioning the filter with $5 \mathrm{~mL}$ of water) per microcosm after gentle stirring of the water using a syringe, approximately $5 \mathrm{~cm}$ under the water surface. Samples for metal analysis were acidified to $0.14 \mathrm{~mol} / \mathrm{L} \mathrm{HNO}_{3}$ (Normatom quality, VWR Prolabo). Ni concentrations were measured using inductively coupled plasma optical emission spectroscopy (ICP-OES; ICAP 7200 DUO; ThermoFisher Scientific; limit of quantification $4 \mu \mathrm{g} \mathrm{Ni} / \mathrm{L}$; method detection limit $1.2 \mu \mathrm{g} \mathrm{Ni} / \mathrm{L}$ ). Samples for cations were taken twice a week, while samples for anions were taken once every two weeks. Cations were measured using ICP-OES. Anions were measured using ion chromatography (Aquamate, Thermo Electron Corporation; Chloride: Merck, Spectroquant 1.14897.001; Sulphate: Merck, Spectroquant 1.14548.001). Samples for measurements of dissolved and total organic and inorganic carbon were taken once a week and were measured with a Total Organic Carbon analyser following the NPOC method (TOC-5000, Shimadzu, Duisburg, Germany; Limit of Quantification 1.5 mg DOC/L; Method Detection Limit 0.5 mg DOC/L). The pH, conductivity,

This article is protected by copyright. All rights reserved. 
temperature and oxygen content of each microcosm was measured before the start and at the end of the photoperiod and this twice a week. The $\mathrm{pH}$ and conductivity were measured using a $\mathrm{pH}$ glass electrode ( $826 \mathrm{pH}$ mobile, Metrohm) and a conductivity meter (WTW cond 315i), respectively. The temperature and oxygen content were measured using an oximeter (WTW oxi 330i).

\section{Sampling and identification of zooplankton and phytoplankton}

Samples for zooplankton and phytoplankton identification were taken from every microcosm each week (starting the day before the start of the first metal addition). Water was collected randomly from several locations (6 to 8, depending on the volume of water that could be collected from every individual location) in the microcosm by lowering a transparent tube (3.3 cm diameter) in the water column just above the sediment surface until a total volume of $600 \mathrm{~mL}$ was collected (Van Regenmortel et al. 2018), representing $12 \%$ of the total microcosm volume. The water was successively filtered through a plankton net with a mesh width of $55 \mu \mathrm{m}$ (for the collection of zooplankton) and a plankton net with a mesh width of $20 \mu \mathrm{m}$ (for the collection of phytoplankton). Afterwards, the filtered water was returned to the microcosms. Both zooplankton and phytoplankton samples were preserved with lugol (0.3\%). Due to practical constraints, plankton samples were identified for the following sampling days: day 0 (test initiation), 14, 28, 42 and 56 (test termination). The identification of zooplankton and phytoplankton was done using an inverted microscope. Macro- and microzooplankton individuals present in the zooplankton samples were identified to the lowest practical taxonomic level and counted. Copepoda were classified as either Cyclopoida or Calanoida and counted. The phytoplankton species in the phytoplankton samples were identified to the 
lowest practical taxonomic level by counting and identifying at least 300 individual cells of a subsample of $30 \mathrm{~mL}$. The abundances per species were afterwards recalculated to numbers per liter. Colonies of colony forming algae were counted as single individuals.

\section{Data analysis}

Data of the microcosm experiment were analysed in terms of the following types of effects: (1) community structure effects: defined as effects on community composition (multivariate analysis with principal response curves) and effects on plankton groups (univariate analysis), (2) effects on individual species (hereafter denoted as 'species effects'; univariate analysis), and (3) functional effects. Three different functional community-level effects were distinguished: (a) overnight community respiration rate which was calculated as $\Delta \mathrm{DO}=D O_{\text {evening day } x}-D O_{\text {morning day } x+1}$ (Downing and Leibold 2002, Van Regenmortel et al. 2018), (b) $\Delta \mathrm{pH}=p H_{\text {evening day } x}-p H_{\text {morning day } x+1}$ which can also be regarded as a proxy for overnight community respiration, because overnight decreases in $\mathrm{pH}$ are governed by $\mathrm{CO}_{2}$ produced during respiration (Brönmark \& Hansson 2005), and (c) the DOC concentration, of which changes during experiments in a closed system gives information about the carbon flows through the microbial loop (accounted for by heterotrophic bacteria and microzooplankton grazers) and the pelagic food web (Van Regenmortel et al. 2018).

Prior to the analysis of community structure effects and individual species effects, abundance values ( $x$, number of individuals per liter) were $\ln (\mathrm{a} x+1)$-transformed, such that when the lowest abundance value is used as $x$ the transformation equals 2 (Van Den

This article is protected by copyright. All rights reserved. 
Brink et al. 2000). This transformation down-weights high abundance values and ensures an approximate log-normal distribution of the data. In practice, the phytoplankton data were $\ln (0.001 x+1)$-transformed and the zooplankton data were $\ln (0.86 x+1)$ transformed.

Community structure effects were evaluated using the principal response curve (PRC) method (Van den Brink \& Ten Braak 1999) in CANOCO 4.5 (Ter Braak \& Smilauer 2002). This method is a multivariate technique, which is based on redundancy analysis ordinations. The method evaluates changes in community structure over time, relative to a control. The statistical significance of $\mathrm{Ni}$ application on community structure was tested using a Monte Carlo permutation test on the ordination axis of the PRC, with the natural logarithm of the dose as an explanatory variable. If Monte Carlo permutation tests revealed a significant effect of $\mathrm{Ni}$ application on the community structure, a LOEC for community structure $\left(\mathrm{LOEC}_{\text {composition}}\right)$ was derived by applying the Williams test on the sample scores, which resulted from the PCA-analysis for each of the sampling occasions

Effects on plankton groups, individual species and community functioning were evaluated by performing univariate analyses with the Williams test. The Williams test assumes an increasing effect (either lower or higher abundance compared to the control) with increasing dose (Williams 1972). The Williams tests were performed in the Community Analysis 4.3.14-software (Hommen et al. 1994). The lowest Ni concentration for which a significant effect on plankton group abundance, species abundance or functional trait was observed was determined to be the $\mathrm{LOEC}_{\text {plankton group, }} \mathrm{LOEC}_{\text {species }}$ and LOEC $_{\text {function, }}$ respectively. The highest Ni concentration for which no significant effect on plankton group abundance, species abundance or functional trait was observed was

This article is protected by copyright. All rights reserved. 
determined to be the $\mathrm{NOEC}_{\text {plankton group }}, \mathrm{NOEC}_{\text {species }}$ and $\mathrm{NOEC}_{\text {function. }}$ Community structure and species abundance effects were calculated separately for the zooplankton and phytoplankton community.

To determine the statistical reliability of the observed effects on individual species, plankton groups and on functional endpoints, a Minimal Detectable Difference (MDD) was calculated for each of these effects on each of the sampling occasion using the Community Analysis 4.3.14-software (Hommen et al. 1994). The MDD expresses the minimum difference, in \%, in the mean abundance of a specific taxon or mean functional response between a Ni treatment and the control that is needed to find a significant effect for the considered endpoint. Hence, the MDD can be considered as a measure of the robustness of the NOEC and LOEC derivation. Brock et al. (2015) proposed to categorize the reliability of the NOEC derivation of a taxon in three MDD categories. In category 1, the MDD must meet at least 1 of the following conditions during the exposure period: (a) $<100 \%$ for at least 5 samplings (not relevant for our sampling frequency); or (b) $<90 \%$ for at least 4 samplings; or (c) $<70 \%$ for at least 3 samplings; or (d) $<50 \%$ for at least 2 samplings. In category 2, the MDD does not meet the criteria for category 1, but a LOEC can be calculated for at least 1 sampling occasion. In category 3, the MDD does not meet the category 1 and 2 criteria. MDDs for all taxa and functional endpoints are listed in Supplemental Information (Table S2.1, Table S3.1 and Table S4.1). Only MDD category $1 \& 2$ species can be used to derive significant effects. Brock et al. (2015) have proposed that at least 8 species belonging to MDD category 1 should be present in a microcosm study to ensure enough statistical power for deriving a regulatory acceptable concentration (RAC), a threshold concentration defined in the framework of pesticide 
regulation in Europe (EFSA 2013). However, in the present study the focus is fundamentally different, as we aimed to evaluate whether the existing threshold concentration for Ni (i.e. HC5) and the currently accepted methods to derive it are protective for community structure and functioning. Hence, we used the MDDs categories to indicate the reliability of each of the endpoints considered, while no specific criterion on the number of taxa within MDD-class 1 was put forward.

For MDD category $1 \& 2$ species, we defined following effects classes: (1) "no significant effect" at any sampling day; (2a) "temporary effect”, i.e. significant effect only on individual sampling days (but excluding the last sampling day); (2b) "effect on the last sampling day" (day 56), while no effects in the same direction were observed on day 42 (indicating the uncertainty about the persistence of the effect over a longer exposure duration); (3) “clear effect with full recovery”, i.e. significant effect in the same direction, observed on at least 2 subsequent sampling dates, but with full recovery observed within the assessment period (i.e. no effects observed on the last sampling day); (4) "clear effect without full recovery" i.e. significant effect in the same direction, observed on at least 2 subsequent sampling dates, without full recovery within the assessment period. The effect classes are based on those that were proposed by Brock et al. (2015) for use in the regulatory frameworks for pesticides, and have been used before to evaluate the protectiveness of the Zn HC5 (Van de Perre et al. 2016).

\section{RESULTS}

Exposure and physico-chemistry

Measured dissolved Ni concentrations before test initiation and in the control microcosms were in most samples lower than the quantification limit of the ICP-OES measurements

This article is protected by copyright. All rights reserved. 
(i.e. $<4 \mu \mathrm{g} \mathrm{Ni} / \mathrm{L}$ ), but always higher than the detection limit (i.e. $>1.2 \mu \mathrm{g} \mathrm{Ni} / \mathrm{L}$ ). In the HC5 and HC50 microcosms, average dissolved Ni concentrations were within $10 \%$ of the targeted dissolved Ni concentrations (Figure 1, Table 1). The pH and oxygen concentrations in the microcosms showed a diurnal fluctuating pattern, which coincided with the photoperiod applied during the exposure period. The $\mathrm{pH}$ at the end of the photoperiod (i.e. evening) in the control microcosms was on average $9.2 \pm 0.5$, and decreased overnight to on average 7.5 \pm 0.5 (Supplemental Information, Figure S1.1). Although $\mathrm{pH}$ increased to relatively high values during the day, $\mathrm{pH}$ values remained within the $\mathrm{pH}$ range reported for the Sinderhoeve pond-system, i.e. pH 7-10 (Portielje, 1994), and for the experimental ditches of the Sinderhoeve site, i.e. pH 7.2-9.2 (Lin et al. 2012). Oxygen at the end of the photoperiod (i.e. evening) in the control microcosms was on average $11.9 \pm 1.1 \mathrm{mg} / \mathrm{L}$, and decreased overnight to on average $8.6 \pm 1.1 \mathrm{mg} / \mathrm{L}$ (Supplemental Information, Figure S1.2). The DOC concentration in the control microcosms at test initiation was on average $13.4 \pm 0.1 \mathrm{mg} / \mathrm{L}$, and increased over the exposure period to $16.6 \pm 4.1 \mathrm{mg} / \mathrm{L}$ at test termination (Figure 2). Ni addition affected both the diurnal patterns of $\mathrm{pH}$ and oxygen, as well as the DOC concentration (described in the 'Effects of Ni on indirect proxies for functional community traits'-section). An overview of the average physico-chemistry in the microcosms is given in Table 1.

Although dissolved Ni concentrations remained relatively stable during the exposure period, changes in $\mathrm{pH}$ and DOC affected Ni bioavailability both over time and between treatments. The bioavailability-normalized HC5 values based on the water chemistry of the HC5 treatment were almost always higher than those calculated based on the water chemistry of the control treatment (Figure 2 right panel). This is mainly due to a slightly

This article is protected by copyright. All rights reserved. 
lower $\mathrm{pH}$ in the HC5 treatment compared to the control treatment (Table 1). In the first four weeks of the exposure period, the bioavailability-normalized HC50 based on the water chemistry of the HC50 treatment was higher than the HC50 calculated based on the water chemistry of the control treatment (Figure 1, right panel). This is related to the lower $\mathrm{pH}$ in the HC50 treatment over the first 4 weeks (Figure S1.1, right panel). The $\mathrm{pH}$ in the HC50 treatment recovered to control levels from week 4 to week 8 . The latter period is also the period in which the decrease in DOC in the HC50 treatment becomes apparent. The latter results in higher Ni bioavailability conditions, as reflected by the lower bioavailability-normalized HC50 in the HC50 treatment compared to the HC50 calculated based on the control chemistry in the last two weeks of the exposure.

\section{Effects of Ni on the phytoplankton community and species}

In total, 46 phytoplankton species belonging to 8 higher taxonomic groups (i.e.

cyanobacteria, chlorophyta, cryptophyta, diatoms, charophyta, chrysophyta, euglenoida and dinophyta) were identified. Among the 8 phytoplankton groups present, 3 fulfilled MDD-criterion 1 and 4 fulfilled MDD-criterion 2 (Table 2), while dinophyta were categorized as MDD-class 3. Among the 46 phytoplankton species present, 1 fulfilled MDD-criterion 1 and 19 fulfilled MDD-criterion 2.

At the start of the exposure period, the phytoplankton community was dominated by cyanobacteria-species (average relative abundance \pm standard error $56 \pm 5 \%$ ), while diatoms, chlorophyta and charophyta represented on average $13 \pm 1 \%, 12 \pm 2 \%$ and $12 \pm 2 \%$ of the individuals identified, respectively (Figure S2.1). Euglenoida (5 $\pm 2 \%$ ), cryptophyta ( $2 \pm 0 \%)$, and chrysophyta $(1 \pm 0 \%)$ were relatively uncommon in the microcosms.

Dinophyta were only recorded in one microcosm on the first sampling day, after which

This article is protected by copyright. All rights reserved. 
they were not recovered from any of the microcosms during the remaining exposure period. Cyanobacteria remained the most important phytoplankton group in the control and HC5 microcosms during the entire exposure period, while in the HC50 treatment the dominance of the cyanobacteria gradually decreased and other groups (chlorophyta, euglenoida and charophyta) became increasingly more important in the phytoplankton community.

The principal response curve diagram of the phytoplankton community is shown in Figure 3 (upper panel). Relatively little variation in community composition was observed at the start of the experiment. Over the entire exposure period, $36 \%$ of the variance depicted in the principal response curve for the phytoplankton community was explained by time, while $21 \%$ of the variance in the phytoplankton community composition was explained by Ni-treatment. Of the total variance explained by Ni, $49 \%$ is depicted in the first PRC-axis (i.e. by the vertical axis in Figure 3), while another 14\% is depicted by the second PRC-axis (not shown). The Monte-Carlo permutation tests showed that the first principal response axis was significant. The Williams test on the PCA sample scores showed that the phytoplankton community composition was not affected by the HC5 treatment (effect class 1), while the community composition was significantly affected in the HC50 treatment from day 14 until the end of the exposure period (effect class 4).

According to the principal response curve analysis, the colony-forming cyanobacteria Oscillatoria sp. 1 was most negatively affected by $\mathrm{Ni}$ exposure (largest positive species weight; $b_{k}$ ). The population dynamics of Oscillatoria sp. 1 in the different Ni treatments is visualized in Figure 4A. While abundances of Oscillatoria sp. 1 in the control and HC5

This article is protected by copyright. All rights reserved. 
treatment increased over the exposure period, the abundance of this species remained largely constant over the exposure period in the HC50 treatment. Hence, Oscilatoria sp. 1 colonies were at least 20-fold less abundant in the HC50 treatment compared to the control after the test initiation. Another species with a relatively high positive species weight was an unknown colony-forming species, for which the population dynamics is visualized in Figure S2.2A. The abundance of this species was 2- to 9-fold lower in the HC50 treatment than in the control treatment. At the other side of the species weights axis, a single cell diatom and an unknown green algae species had the strongest negative species weights, indicating that the abundances of these species were positively affected by Ni. The abundances of the single cell diatoms decreased rather drastically over the exposure period in the control microcosms, i.e. a 10-fold difference was observed between the abundance on day 0 and day 56 (Figure 4B). This decrease in the abundance of the single cell diatoms was less explicit in the HC50 cosms (i.e. only a 2-fold decrease was noted over the same time period). The 'unknown green algae colony' was not observed in any of the control microcosms throughout the exposure period, while the species was reported in the HC5 and/or HC50 cosms from day 28 onwards (Figure S2.2B). The species even dominated the chlorophyta community in the HC50 cosms at the end of the exposure period (i.e. on average $50 \pm 25 \%$ of the chlorophyta were identified to be the 'unknown green algae colony').

The results of the analysis of the effect of $\mathrm{Ni}$ on the abundance of the different phytoplankton groups and species is summarised in Table 2. Focusing on the community structure level, the total abundance of the phytoplankton community was significantly affected by Ni addition (Figure 5, upper left panel). From exposure day 28 until the end 
of the exposure period, a significant decrease in total algae densities was observed in the HC50 treatment (effect class 4). In this period; the phytoplankton densities decreased by at least 2-fold compared to the control. Total phytoplankton abundance was also significantly affected in the HC5 treatment, but only on a single sampling date (effect class 2a). The cyanobacteria and diatoms were significantly affected in the HC50 treatment without recovery occurring at the end of the exposure period (effect class 4). Cyanobacteria densities were significantly lower in the HC50 microcosms compared to the control treatments from day 28 until the end of the exposure period (at least a 6.5-fold difference in cyanobacteria densities was observed; Figure 5 upper row, middle panel). Diatom densities, on the other hand, increased significantly in the HC50 cosms, and this already at the first sampling day after the first Ni addition (Figure 5 middle row, middle panel). Diatoms were on average at least 3-fold more abundant in the HC50 cosms than in the control cosms. Effects occurring only on a single sampling day, excluding the last sampling day (class 2a effects), were observed for the cyanobacteria (day 28), Crysophyceae (day 42) and Cryptophyceae (day 42) in both the HC5 and HC50 treatment.

At the species level, clear effects without recovery (class 4) were reported for two phytoplankton species in the HC50-treatment, a cyanobacteria (Oscillatoria sp. 1) and a diatom (single cell diatoms), while clear effects with recovery (class 3) were observed for the species Staurastrum. Oscillatoria sp. 1 densities were significantly negatively affected in both the HC5 and HC50 treatment on sampling days 14 and 28 (Figure 4.A). However, Oscillatoria sp. 1 densities in the HC5-treatment recovered to control levels on sampling days 42 and 56 (class 3), whereas the significant negative effect persisted in the 
HC50-treatment until the end of the exposure period (class 4). The abundance of single cell diatoms increased significantly compared to the control in the HC50-treatment, and this from the first sampling day after the Ni addition until the end of the exposure period (Class 4; Figure 4.B). Abundances of the two Charophyta species increased significantly in the HC50 treatments compared to the controls on day 14 and 28 (Class 3; Figure S3.2.C \& D). Slight effects (Class 2b) at the HC5 and at the HC50 were observed for 3 and 11 species, respectively. In addition, for 1 species (Chroococcus) significant effects were observed in the HC5 treatment on the last sampling day, while no such effects (at least in the same direction) were observed on day 42 ( effect class 2b). In the HC50 treatment, 6 species were affected on the last sampling, while no effect was observed on day 42 (effect class 2b).

\section{Effects of Ni on the zooplankton community and species}

In total, 35 zooplankton species belonging to 4 zooplankton groups (i.e. copepoda, cladocera, rotifer and ostracoda) were identified. All zooplankton groups fulfilled MDDcriterion 1, except the ostracoda group which was classified as MDD class 3. Five zooplankton species fulfilled MDD-criterion 1 and 13 zooplankton species fulfilled MDD-criterion 2. At the start of the exposure period the zooplankton community was dominated by copepods (average relative density \pm standard error $51 \pm 1 \%$ ), while rotifers and cladocera represented on average $28 \pm 2 \%$ and $20 \pm 1 \%$ of all individuals in the community (Supplemental Information; Figure S3.1). Ostracoda were not observed in any of the microcosms at the beginning of the exposure period and ostracoda-abundances remained low throughout the exposure period (relative abundance was maximally $1 \%$ ). In the control and HC5 microcosms, the relative abundances of the copepods and rotifers 
became almost equal near the end of the exposure period, while the relative abundance of the cladocerans decreased to $10 \%$ near the end of the exposure period. In the HC50 cosms, the cladocerans almost disappeared from the zooplankton community, representing only $3 \%$ of the total zooplankton, while rotifers dominated the zooplankton community at the end of the exposure period (relative abundance 62\%).

The principal response curve diagram depicts the effects of $\mathrm{Ni}$ on the zooplankton community (Figure 3, lower panel). Relatively little variation in community composition was observed between treatments at the start of the experiment. Over the exposure period, the principal response curve explained $42 \%$ of the variance depicted in the zooplankton community composition by time, while $19 \%$ of the variance in the zooplankton community composition was explained by Ni-treatment. Of the total variance explained by the Ni-treatment, $38 \%$ is depicted in the first PRC-axis (i.e. by the vertical axis in Figure 3), while another 21\% is depicted by the second PRC-axis (not shown). The Monte-Carlo permutation tests showed that the first principal response axis was significant. The Williams test on the PCA sample scores showed that the zooplankton community composition was significantly affected in the HC5 microcosms only on day 28 (effect class 2 ), while the community composition was significantly affected in the HC50 cosms on day 28 and day 42 (effect class 3). Although the PRCcurve of the zooplankton also indicates effects at day 56, Williams-testing on PCA sample scores did not reveal significant effects at this sampling moment in either the HC5 or HC50 treatment.

The rotifer species 'Asplanchna/Testidunella sp.' had the largest positive species weight $\left(b_{k}\right)$ within the PRC (Figure 3, right lower panel), indicating that this species was most 
negatively affected by Ni exposure. Figure S3.2 shows the abundance of this species during the exposure period. The rotifer species ‘Asplanchna/Testidunella sp.' almost completely disappeared from the HC50 microcosms after 42 days of exposure. Other species with high species weights (i.e. absolute $b_{k}>1$ ) in the PRC diagram did not show any clear effects from Ni addition.

The results of the analysis of the effects of Ni on the zooplankton community structure (PRC and abundance of the different zooplankton groups) and species abundances are summarised in Table 3. At the community structure-level, Ni only affected the total abundance of the zooplankton community on day 28 and this only in the HC50 treatment (effect class 2a). The zooplankton group copepoda showed the same response. The abundance of all other higher taxonomic zooplankton groups (i.e. rotifers, cladoceran \& ostracoda) were not significantly affected by any of the Ni treatments (effect class 1 ; Figure 6).

At the zooplankton species-level, only two species showed clear effects (i.e. on two consecutive sampling days), the rotifers 'Asplanchna/Testidunela sp' and 'Trichocerca group similis’ (Figure S3.2). The rotifer species ‘Asplanchna/Testidunela sp’ was significantly less abundant in the HC50 treatment on the last two exposure days (effect class 4), which was also indicated in the PRC-graph (discussed above). For the species 'Trichocerca group similis', a significant decrease in abundance in both the HC5 and HC50 microcosm was observed on day 14 and day 28 of the exposure period, but not later on (effect class 3). Slight effects, i.e. effects observed on individual sampling days (Class 2a) were observed for an additional 6 and 7 species in the HC5 and HC50 treatments, respectively. In addition, for 3 species (Ascomorpha saltans, Alona guttata

This article is protected by copyright. All rights reserved. 
and Acroperus harpae) significant effects were observed in the HC5 treatment on the last sampling day, while no effects in the same direction were observed on day 42 (effect class 2b). In the HC50 treatment, 6 species were affected on the last sampling, while no effect was observed on day 42 (effect class 2b).

\section{Effects of Ni on indirect proxies for functional community traits}

The community respiration, measured as overnight change in dissolved oxygen concentration $\left(\Delta \mathrm{O}_{2}\right)$, was clearly affected by $\mathrm{Ni}$ addition (i.e. on at least 2 consecutive days) between day 17 and 31 (Figure 7, upper panel). In this period, overnight respiration was significantly decreased in the HC50 treatment, compared to the control (effect class 3). The overnight decrease in $\mathrm{pH}(\Delta \mathrm{pH})$, an additional proxy for overnight respiration, increased steadily in the control microcosms from $1.5 \pm 0.1 \mathrm{pH}$-units at test initiation to $2.3 \pm 0.2 \mathrm{pH}$-units at the end of the exposure period (Figure 7, lower panel). A similar trend in overnight decreases in $\mathrm{pH}$ was observed in the HC5 treatment, but this overnight change in $\mathrm{pH}$ was significantly lower in the HC50 treatment from day 3 to day 31 after the first $\mathrm{Ni}$ application (effect class 3). Near the end of the exposure period the $\Delta \mathrm{pH}$ and $\Delta \mathrm{O}_{2}$ in the HC50 cosms recovered to control levels.

The DOC concentration, which is a proxy for the carbon cycling through the microbial loop and pelagic food web interactions, increased slightly over the exposure period in the control and HC5 microcosms, but DOC decreased over the exposure period in the HC50 treatment (Figure 2). The difference in DOC concentrations between the control treatments and the HC50 treatments became significant from exposure day 28, and remained significant until the end of the exposure period (effect class 4). 


\section{DISCUSSION}

For phytoplankton, the effects of $\mathrm{Ni}$ on the community structure (community composition and plankton group abundances) became apparent relatively early after the first $\mathrm{Ni}$ application. The early onset of changes in the community structure after $\mathrm{Ni}$ application was mainly driven by a single cyanobacteria species, i.e. Oscillatoria $s p .1$. This species appears to be directly affected by $\mathrm{Ni}$, because while Oscillatoria $s p .1$ showed a relatively steep population growth in the control microcosms no net growth was observed in the HC50 treatment (Figure 4A). Moreover, in the control microcosms Oscillatoria sp. 1 became increasingly more important in the phytoplankton community, and was the dominant species in these control communities from exposure day 28 onwards (Figure 4.C). The effects observed on other phytoplankton species can largely be explained by indirect effects occurring in the community, likely due to a lower competition pressure exerted by Oscillatoria sp. 1 in the HC50 microcosms, i.e. competitive release (Fleeger et al. 2003). The decrease in Oscillatoria sp. 1 abundance created the opportunity for diatoms, and especially the single cell diatoms, to maintain a population in the HC50 treatments, while diatoms were outcompeted by Oscillatoria sp. 1 in the control

microcosms (Figure 4). This pattern was also observed in our control microcosms: at the start of the exposure period abundances of Oscillatoria sp. 1 were low (only 1.5\% of the total algae cells/colonies), while single cell diatoms were in comparison more abundant (12.5\% of the total algae cells/colonies) (Figure 4C). At the first sampling day, Oscillatoria sp. 1 densities increased 14-fold compared to the test initiation, and single cell diatom densities decreased more than 2-fold. Over the exposure period, Oscillatoria sp. 1 became the dominating species in the control microcosms, while single cell diatoms 
further decreased. In the HC50 microcosms on the other hand, both Oscillatoria sp. 1 and single cell diatoms densities remained relatively constant over the exposure period. The densities of two other phytoplankton species were also positively affected by exposure to HC50, the Charophyta Staurodesmus sp. and Staurastrum sp. Hence, it is possible that these species were also indirectly affected by the reduced competition with Oscillatoria sp. 1, although abundances of these species remained relatively low and effects became non-significant near the end of the exposure period. Although abundances of single diatoms and Staurodesmus sp. and Staurastrum sp. increased in the HC50-cosms compared to the control microcosms, the total algae abundance was still negatively affected in the HC50 microcosms, perhaps because they could not entirely compensate for the lower growth of the Oscillatoria sp. 1 in these microcosms.

Ni application had a clear effect on all three chemical parameters used as proxies for community functioning. These effects on community functioning were most likely also governed by the effect of $\mathrm{Ni}$ on Oscillatoria $s p .1$. Both proxies for overnight respiration (measured as $\Delta \mathrm{O}_{2}$ and $\Delta \mathrm{pH}$ ) were significantly decreased in the HC50 microcosms from day 17 through to day 31 of the exposure period. This period corresponds with the period of maximal population growth of the most dominant algal species in the control microcosms, Oscillatoria sp. 1 (Figure 4.C). After this period, community respiration recovered to control levels near the end of the exposure period. The latter coincides with the decreased importance of Oscillatoria sp. 1 within the algae community (Figure 4.C). DOC was used as a proxy for the cycling of carbon through the community. This is because DOC, which originates from the exudates of phytoplankton, inefficient zooplankton feeding or the breakdown of organic particles, supports the bacterial 
production in freshwater ecosystems, which then fuels higher trophic levels through the food web (Leff 2009). In the present study, the decreased DOC concentrations in the HC50 treatments were most likely caused by a decreased phytoplankton abundance in the HC50 treatments, which in turn generated a lower input of DOC to the microbial loop compared to the control microcosms. In addition, DOC concentrations in the HC50 treatment decreased over time. Decreases in DOC concentrations are an indication that the consumption of DOC by bacteria is higher than the DOC production. In the control and HC5 microcosms, DOC concentrations increased over time. The latter can be explained by a higher DOC input as the bloom of cyanobacteria progressed. Senescent algae are an important carbon source for the microbial loop, and especially at the end of algae blooms high levels of carbon are released (Brönmark \& Hansson 2005).

Chemicals can affect species of higher trophic levels, such as consumers, either directly or indirectly. Indirect effects occur due to changes in algae community structure and composition, which may affect consumers through alterations in food quality and quantity (Fleeger et al. 2003). Overall, the effects of Ni addition on the zooplankton community were limited. Despite the adverse effect of $\mathrm{Ni}$ on the zooplankton community structure, only two zooplankton species (the rotifers 'group Asplanchna/Testidunela sp.' and 'Trichocerca group similis') showed clear effects of Ni (effect class 3 or 4). The effect of $\mathrm{Ni}$ on these species can most likely be considered as a 'direct' effect. This is because the abundance of these rotifers decreased, although general food quality for rotifers improved in the HC50 treatment as non-edible cyanobacteria densities decreased in favour of more suitable food sources like diatoms (Oganjan et al. 2013). This is somewhat unexpected, because the only rotifer currently included in the chronic Ni SSD,

This article is protected by copyright. All rights reserved. 
B. calyciflorus, is also the least sensitive of all zooplankton-species included in the SSD (i.e. the bioavailable-normalized EC10 is $320 \mu$ g dissolved $\mathrm{Ni} / \mathrm{L}$ ). This suggests that the Ni sensitivity of B. calyciflorus is not representative for all rotifer species.

The most important effects (either direct or indirect) occurring in the microcosms after $\mathrm{Ni}$ application are summarized in Figure 8. Overall, the observed effects of $\mathrm{Ni}$ in the present study are relatively similar to the effects of a ternary $\mathrm{Ni}-\mathrm{Zn}-\mathrm{Cu}$ mixture on the same planktonic community (described in Van Regenmortel et al. 2018). Van Regenmortel et al. (2018) also reported strong direct effects of the metal mixture on Oscillatoria sp. 1 and rotifer abundances, and indirect effects on diatom abundances. In addition, the physico-chemical proxies for community functioning $\left(\Delta \mathrm{pH}, \Delta \mathrm{O}_{2}\right.$ and DOC) were affected in a similar manner. However, unlike in our test system, the ternary $\mathrm{Ni}-\mathrm{Zn}-\mathrm{Cu}$ mixture also affected copepods (directly) and Charophyta and Cryptophyta (indirectly). Hommen et al. (2016) reported on the effects of long-term (4 months) Ni exposure on an aquatic community at a rather high Ni bioavailability (low DOC). In their study, they observed long-term adverse effects on some phytoplankton species (Cryptophyceae) and on snails. In addition, indirect effects through decreased competition were observed for Chlorophyceae, while the zooplankton remained mostly unaffected.

The indirect effects of Ni on its own bioavailability

Although the average measured $\mathrm{Ni}$ concentrations were relatively stable over time, $\mathrm{Ni}$ bioavailability varied because the physico-chemistry of the exposure solutions changed during the exposure period. $\mathrm{pH}$ and $\mathrm{DOC}$ changed over the exposure period as a consequence of the community functioning. However, the evolution of $\mathrm{pH}$ and $\mathrm{DOC}$

This article is protected by copyright. All rights reserved. 
differed between the different $\mathrm{Ni}$ treatments. Given that $\mathrm{pH}$ and $\mathrm{DOC}$ are important factors in determining Ni bioavailability (Deleebeeck et al. 2007; 2008; 2009; Nys et al. 2016), Ni thus has the ability to indirectly influence its own bioavailability (Figure 1, right panel). Similar effects of a metal indirectly influencing its own bioavailability have already been reported for Zn (Van de Perre et al. 2016). The changes in DOC and pH and the indirect effects of $\mathrm{Ni}$ on its own bioavailability via its direct effect on community functioning somewhat complicates the interpretation of the effects occurring in the microcosm, as these changes also bring about a variation of the calculated potentially affected fraction (PAF) of the species over the exposure period and between nickel treatments. Using the bioavailability-based SSD normalization based on the water chemistry in the control treatment as a reference to determine the PAFs in the $\mathrm{Ni}$ treatments, the PAF ranged between 4\% and 9\% in the HC5 treatment and between $43 \%$ and 53\% in the HC50 treatment (Figure S5.1). The PAF increased over time, supporting the idea that $\mathrm{Ni}$ bioavailability increased during the exposure period. This increased $\mathrm{Ni}$ bioavailability was mainly the result of the increased $\mathrm{pH}$, which dominated over the bioavailability-reducing effects of the increased DOC concentrations over the exposure period. Although Ni bioavailability changed over time, the PAF remained relatively stable over time. Furthermore, as changes in bioavailability lead to calculated PAFs in the HC5 treatment that are higher than 5\%, our evaluation of the protectiveness of the HC5 for our investigated community is somewhat at the conservative side from a regulatory point of view. Hence, despite the changes in bioavailability, our initial research question, whether the HC5 is protective for community structure and functioning, can still be reliably answered with our study.

This article is protected by copyright. All rights reserved. 
Conclusions and implications for Ni risk assessment

In the present study, we observed that the bioavailability-normalised HC50-treatment had clear effects (i.e. effect classes 3 and 4) on both the structure and functioning of our algae and zooplankton-dominated aquatic community. In contrast, at the bioavailabilitynormalised HC5, no clear effects on community structure (composition of phytoplankton and zooplankton community and abundance of plankton species groups) or functioning (community respiration and carbon cycling) were observed, although some endpoints were significantly affected on individual sampling days (effect class 2a).

At the species level, some clear effects (i.e. on at least two consecutive sampling days) in the HC5 treatment appeared early in the exposure period, but did not persist after day 28 of the exposure (effect class 3). Hence, the abundances of the populations of these species tended to recover after initially being affected. In addition, significant effects in the HC5 treatment on the species level on single individual sampling days were observed (effect class 2a and 2b) for 4 phytoplankton species (of in total 19 MDD-class $1 \& 2$ species) and 9 zooplankton species (of 18 MDD-class $1 \& 2$ species). For 3 zooplankton species (A. saltans, A. guttata and A. harpae) and 1 phytoplankton species (Chroococcus), effects in the HC5 treatment appeared only on the last sampling day (effect class 2b). For these 4 species, the long-term outcome of the effect at the HC5 is uncertain, as effects may or may not have persisted if the exposure duration would have been extended after day 56 .

Overall, based on the present study the procedure to derive the HC5 as currently implemented in European legislative frameworks, which includes bioavailability normalisations of toxicity data to the physico-chemistry of the receiving waters, protects

This article is protected by copyright. All rights reserved. 
against clear effects on plankton community structure and function at high DOC. The latter is in agreement with the conclusion of Hommen et al. (2016) for a planktonic dominated community at lower DOC concentrations. Our study also showed that some individual plankton species are affected at the HC5, but this is not in conflict with the definition of the HC5, at which 95\% (and not 100\%) of the species are predicted to be unaffected.

In the present study, the community composition was assessed every two weeks. We acknowledge that a more frequent assessment could have been more informative to evaluate the effects of $\mathrm{Ni}$, especially on individual phytoplankton species. Given the potentially fast dynamics of phytoplankton populations, some of effects in the phytoplankton community may have been missed. As such, the conclusions of the protectiveness of the HC5 for the phytoplankton community should be interpreted somewhat more cautiously than the conclusions for the zooplankton community.

Within the WFD and REACH, the relevance of a community-level study for deriving an EQS or PNEC lies in the fact that it can support the choice of an assessment factor for the HC5 derived with an SSD-based method, which is based on species sensitives derived from chronic lab toxicity tests with single species (EC 2003, EC 2011). The WFD prescribes a set of criteria to assess the quality of a community-level study for supporting the assessment factor derivation, among which the presence of sensitive species (EC 2011). Community-studies are considered most relevant if the community contains species that are known to be sensitive to the contaminant. At the specific water chemistry conditions of our microcosm studies, cladocerans are among the most sensitive species in the chronic Ni SSD (Table S5). Ten different cladoceran species were recorded in our 
experiment and at least two of the sensitive cladoceran species present in the SSD were also observed in our test system. The fact that Lymnaea stagnalis, the most sensitive species in the current Ni SSD, was not assessed in the present study could be considered a weakness of our study from a regulatory point of view. On the other hand, a clearly sensitive cyanobacterium (Oscillatoria sp.) showing clear effects at the HC5 treatment (23 $\mu \mathrm{g}$ dissolved $\mathrm{Ni} / \mathrm{L}$ ) was present in our community. This concentration is approximately 4-fold lower than bioavailability-normalized EC10 of the most sensitive phytoplankton species in the current Ni-SSD (92 $\mu \mathrm{g} / \mathrm{L}$; Scenedesmus accuminatus; Table S5). The higher sensitivity of cyanobacteria compared to chlorophytes observed in this study is supported by the studies of Wang \& Wood (1984) and Chakraborty et al. (2010). In addition, Martinez-Ruiz et al. (2016) reported an EC50 and EC10 for the cyanobacterium Microcystis aeruginosa as low as 3.7 and $0.7 \mu \mathrm{g} / \mathrm{L}$ (nominal $\mathrm{Ni}$ ) in high bioavailability conditions (low DOC). Normalisation of the Ni SSD to the growth medium used by Martinez-Ruiz et al. (2016; AAP-medium) results in a bioavailabilitynormalized EC10 for $L$. stagnalis of $1.0 \mu \mathrm{g} / \mathrm{L}$ (dissolved Ni; Table S5.3). Hence, $M$. aeruginosa might show a similar sensitivity as $L$. stagnalis, although this requires confirmation with a $M$. aeruginosa toxicity test in which the (low) Ni exposure concentrations are analytically confirmed by measurements during the experiment. Regardless, given the presence and evaluation of cladocerans and cyanobacteria in our test system, the regulatory requirement of the presence of sensitive species in microcosm studies is sufficiently fulfilled in the present study to enable a reliable evaluation of the protectiveness of the bioavailability-normalized HC5

This article is protected by copyright. All rights reserved. 
The above discussion also indicates that the toxicity data of the algae species now included in the SSD may not be entirely representative of the sensitivity of species in actual phytoplankton communities, an observation which was previously also made in the study of Hommen et al. (2016). According to the bioavailability normalized SSD, zooplankton are considerably more sensitive for Ni than phytoplankton. For instance, the bioavailability-normalised EC10 of the most sensitive zooplankton species (Ceriodaphnia dubia) was 6-fold lower than that of the most sensitive phytoplankton species (Scenedesmus accuminatus) (Table S5). However, in the present study the effects of $\mathrm{Ni}$ on the zooplankton community were relatively limited, while the phytoplankton community showed a higher sensitivity. Similar observations have been made in previous community studies with Ni (Hommen et al. 2016), Zn (Van de Perre et al. 2016) and NiZn-Cu mixtures (Van Regenmortel et al. 2018). The most likely explanation for this is that there exists a mismatch between the species in an SSD and species in natural communities (Van Regenmortel et al. 2018). For instance, all phytoplankton species currently included in the Ni SSD are Chlorophyta, while this taxonomic group seems to be relatively insensitive to $\mathrm{Ni}$. On the other hand, the most sensitive phytoplankton group in the present study, Cyanobacteria and more specifically the species Oscillatoria sp. 1, is currently not represented in the Ni SSD. Overall, this shows that - although our study supports that the SSD-method is protective for community structure and functioning SSDs cannot be used to predict species sensitivity rankings in community studies.

Supplemental Data—The Supplemental Data are available on the Wiley Online Library at DOI: 10.1002/etc.xxxx

This article is protected by copyright. All rights reserved. 


\section{ACKNOWLEDGMENT}

This work was supported by NiPERA, Inc. .The authors thank L. Moerman, D. Van de Perre, M. Vanderborght, E. Pequeur, N. De Saeyer, J. Depecker, and G. Bockstael for their help with the toxicity tests and for the chemical analyses. We thank our anonymous reviewers for their useful comments, which improved the manuscript.

Data accessibility- Data for this study are publicly available via FigShare at DOI:xxxx. This article has earned an Open Data/Materials badge for making publicly available the digitally-shareable data necessary to reproduce the reported results. The data is available at xxx. Learn more about the Open Practices badges from the Center for Open Science: https://osf.io/tvyxz/wiki.

\section{REFERENCES}

Artigas J, Pascault N, Bouchez A, Chastain J, Debroas D, Humbert JF, Leloup J, Tadonleke RD, ter Halle A, Pesce S. 2014. Comparative sensitivity to the fungicide tebuconazole of biofilm and plankton microbial communities in freshwater ecosystems. Sci Tot Environ 468: 326-336.

Brock TCM, Hammers-Wirtz M, Hommen U, Preuss TG, Ratte HT, Roessink I, Strauss T, Van den Brink PJ. 2015. The minimum detectable difference (MDD) and the interpretation of treatment-related effects of pesticides in experimental ecosystems. Environ Sci Pollut Res 22: 1160-1174.

Brönmark C, Hansson LA. 2005. The biology of lakes and ponds. $2^{\text {nd }}$ edition. Oxford University Press, Oxford, United Kingdom.

Chackraborty P, Babu PVR, Acharyya T, Bandyopadhyay D. 2010. Stress and toxicity of biologically important transition metals (Co, Ni, Cu and Zn) on phytoplankton in a

This article is protected by copyright. All rights reserved. 
tropical freshwater system: An investigation with pigment analysis by HPLC.

Chemosphere 80: 548-553.

DEPA [Danish Environmental Protection Agency]. 2008. European Union Risk Assessment Report (EU RAR) of nickel and nickel compounds prepared by the Danish Environmental Protection Agency (DEPA). Available on: http://echa.europa.eu/documents/10162/cefda8bc-2952-4c11-885f-342aacf769b3. Last accessed: 28/06/2018.

Deleebeeck NME, De Schamphelaere KAC, Janssen CR. 2007. A bioavailability model predicting the toxicity of nickel to rainbow trout (Oncorhynchus mykiss) and fathead minnow (Pimephales promelas) in synthetic and natural waters. Ecotoxicol Environ Saf 67: 1-13.

Deleebeeck NME, De Schamphelaere KAC, Janssen CR. 2008. A novel method for predicting chronic nickel bioavailability and toxicity to Daphnia magna in artificial and natural waters. Environ Toxicol Chem 27: 2097-2107.

Deleebeeck NME, De Schamphelaere KAC, Janssen CR. 2009. Effects of $\mathrm{Mg}^{2+}$ and $\mathrm{H}^{+}$ on the toxicity of $\mathrm{Ni}^{2+}$ to the unicellular green alga Pseudokirchneriella subcapitata: model development and validation with surface waters. Sci Total Environ 407: 19011914.

Del Signore A, Hendriks AJ, Lenders HJR, Leuven RSEW, Breure AM. 2016. Development and application of the SSD approach in scientific case studies for ecological risk assessment. Environ Toxicol Chem 35: 2149-2161.

Downing AL, Leibold MA. 2002. Ecosystem consequences of species richness and composition in pond food webs. Nature 416: 837-841.

EC [European Commission]. 2003. Technical guidance document on risk assessment. Part 3 Environmental risk assessment. Available on: https://echa.europa.eu/documents/10162/16960216/tgdpart3_2ed_en.pdf . Last accessed: 23/10/2018.

This article is protected by copyright. All rights reserved. 
EC [European Commission]. 2011. Technical guidance document on deriving environmental quality standards. ISBN : 978-92-79-16228-2

EC [European Commission]. 2013. Directive 2013/39/EU of the European Parliament and of the Council of 12 August 2013 amending Directives 2000/60/EC and 2008/105/EC as regards priority substances in the field of water policy. Official Journal of the European Communities, Brussels, Belgium.

EFSA [European Food Safety Authority]. 2013. Guidance on tiered risk assessment for plant protection products for aquatic organisms in edge-of-field surface waters. EFSA Journal 11 (7): 3290.

ECHA [European Chemicals Agency]. 2008. Guidance on information requirements and chemical safety assessment. Appendix R.7.13-2: Environmental risk assessment for metals and metal compounds. ECHA, Helsinki, Finland.

Fleeger JW, Carman KR, Nisbet RM. 2003. Indirect effects of contaminants in aquatic ecosystems. Sci Tot Environ 317: 207-233.

Hommen U, Veith D, Ratte HT. 1994. A computer program to evaluate plankton data from freshwater field tests. In Hill IR, Heimbach F, Leeuwangh P, Matthiessen P, eds, Freshwater Field Tests for Hazard Assessment of Chemicals. Lewis, Boca Raton, FL, USA, pp 503-513.

Hommen U, Knopf B, Rüdel H, Schäfers C, De Schamphelaere KAC, Schlekat C, Garman ER. 2015. A microcosm study to support aquatic risk assessment of nickel: Community-level effects and comparison with bioavailability-normalized species sensitivity distributions. Environ Toxicol Chem 35: 1172-1182.

Johnston EL, Mayer-Pinto M, Crowe TP. 2015. Review: chemical contaminant effects on marine ecosystem functioning. J Appl Ecol 52: 140-149.

Leff LG. Freshwater habitats in Encyclopedia of Microbiology (third edition).Ed.: Schaechter M, Academic Press, Cambridge, Massachusetts, USA.

This article is protected by copyright. All rights reserved. 
Lin R, Buijse L, Dimitrov MR, Dohmen P, Kosol S, Maltby L, Roessink I, Sinkeldam JA, Smidt H, Van Wijngaarden RPA, Brock TCM. 2012. Effects of the fungicide metiram in outdoor freshwater microcosms: responses of invertrebrates, primary producers and microbes. Ecotoxicology 21: 1550-1569.

Martinez-Ruiz EB, Martinez-Jeronimo F. 2016. How do toxic metals affect harmful cyanobacteria? An integrative study with a toxigenic strain of Microcystis aeruginosa exposed to nickel stress. Ecotoxicol Environ Safe 133: 36-46.

Nys C, Janssen CR, Van Sprang P, De Schamphelaere KAC. 2016. The effect of pH on chronic aquatic $\mathrm{Ni}$ toxicity is dependent on the $\mathrm{pH}$ itself: extending the chronic $\mathrm{Ni}$ bioavailability models. Environ Toxicol Chem 35: 1097-1106.

Oganjan K, Virro T, Lauringson V. 2013. Food spectrum of the omnivorous rotifer Asplanchna priodonta in two large northeastern European lakes of different trophy. Oceanol Hydrobiol St 42: 314-323.

Portielje R. 1994. Response of Shallow Aquatic Ecosystems to Different Nutrient Loading Levels. Phd Wageningen, The Netherlands.

Posthuma L, Traas TP, Suter II GW. 2000. General introduction to species sensitivity distribution. In Posthuma L, Traas TP, Suter II GW (Eds). Species sensitivity distributions in ecotoxicology. Lewis Publishers, Boca Raton (FL), USA.

Rorh JR, Crumrine PW. 2005. Effects of an herbicide and an insecticide on pond community structure and processes. Ecol appl 15: 1135-1147.

Roussel H, Chauvet E, Bonzom JM. 2008. Alteration of leaf decomposition in coppercontaminated freshwater mesocosms. Environ Toxicol Chem 27(3): 637-644.

Schlekat CE, Van Genderen E, De Schamphelaere KAC, Antunes PMC, Rogevich E, Stubblefield WA. 2010. Cross-species extrapolation of chronic nickel biotic ligand models. Sci Tot Environ 408: 6148-6157.

This article is protected by copyright. All rights reserved. 
Ter Braak CJF, Smilauer P. 2002. CANOCO Reference Manual and CanoDRAW for Windows User’s Guide: Software for Canocical Community Ordination, Ver 4.5. Microcomputor Power, Ithaca, NY, USA.

Van Den Brink PJ, Hattink J, Bransen F, Van Donk E, Brock TCM. 2000. Impact of the fungicide carbendazim in freshwater microcosms. II. Zooplankton, primary producers and final conclusions. Aquat Toxicol 48: 251-264.

Van Den Brink PJ, Ter Braak CJF. 1999. Principal Response Curves : Analysis of TimeDependent Multivariate Responses of Biological Community To Stress. Environ Toxicol Chem 18: 138-148.

Van de Perre D, Roessink I, Janssen CR, Smolders E, Van Regenmortel T, Van Wichelen J, Vyverman W, Van den Brink PJ, De Schamphelaere KAC. 2016. The effects of zinc on the structure and functioning of a freshwater community: a microcosm experiment. Environ Toxicol Chem 29: 730-741.

Van Regenmortel T, Van de Perre D, Janssen CR, De Schamphelaere KAC. 2018. The effects of a mixture of copper, nickel, and zinc on the structure and function of a freshwater planktonic community. Environ Toxicol Chem 37: 2380-2400.

Wang H-K, Wood JM. 1984. Bioaccumulation of Nickel by algae. Environ Sci Technol 18: $106-109$.

Williams DA (1972) The comparison of several dose levels with a zero dose control. Biometrics 28:519-531

This article is protected by copyright. All rights reserved. 


\section{FIGURES}

Figure 1. A) Dissolved Ni concentrations measured over the entire exposure duration in the microcosms of the HC5 (diamonds) and HC50 treatment (triangles). All data-points are the average measurement of 3 replicates. Open symbols represent measurements of samples taken before $\mathrm{Ni}$ addition, filled symbols represent measurements of samples taken 15 to 35 minutes after Ni addition. Dashed lines represent the nominal targeted dissolved Ni concentration (i.e. 24 and $97 \mu$ g dissolved Ni/L). B) Bioavailability normalized HC5 (data points connected with dashed line) and HC50 (data points connected with full line). Bioavailability normalizations were performed based on measured water chemistry of the control treatment (open circles), HC5 treatment (filled diamonds) and HC50 treatment (filled triangle) using the chronic Ni bioavailability tool (Nys et al. 2016). The entire chemistry used for bioavailability-normalization is given in Table S2.2.
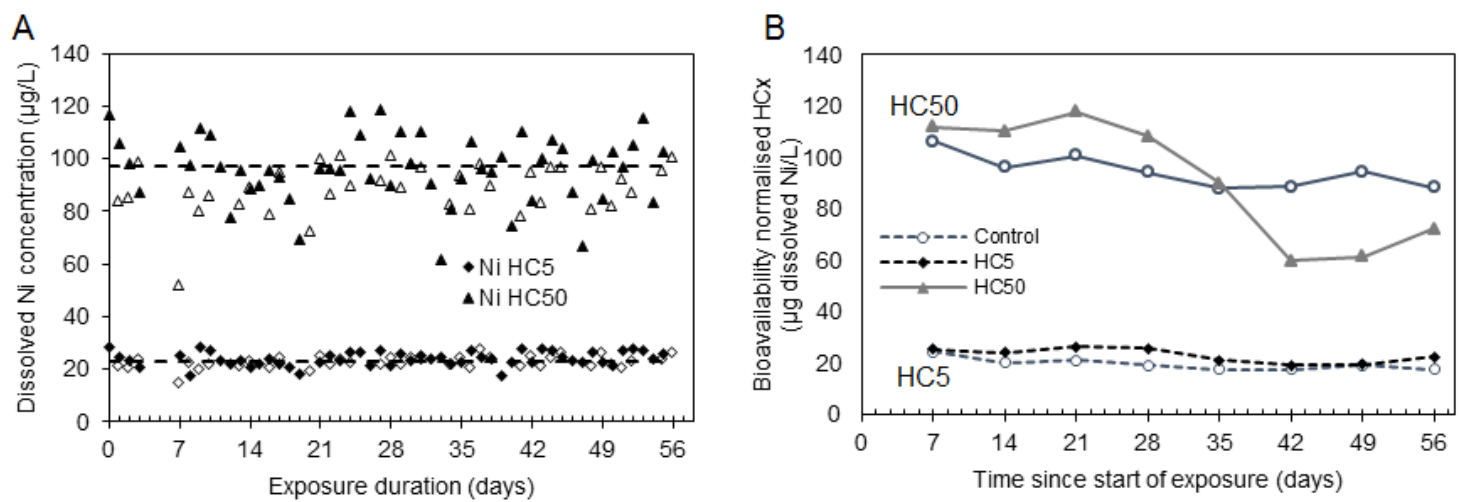

This article is protected by copyright. All rights reserved. 
Figure 2. Dissolved Organic Carbon (DOC) concentrations over the entire exposure duration in the microcosms of the control (squares), HC5 (diamonds) and HC50 treatment (triangles). Error bars indicate standard deviation on the average based on 4 (control) and 3 replicates (HC5, HC50). Asterisks indicate significant differences in DOC concentrations relative to the DOC concentration in the control microcosms. Calculated lowest-observed-effect concentrations (LOEC) are indicated above the graph for every sampling day (Williams test, $\mathrm{p}<0.05$ ). If nothing is plotted this indicates that the LOEC was higher than the highest Ni treatment.

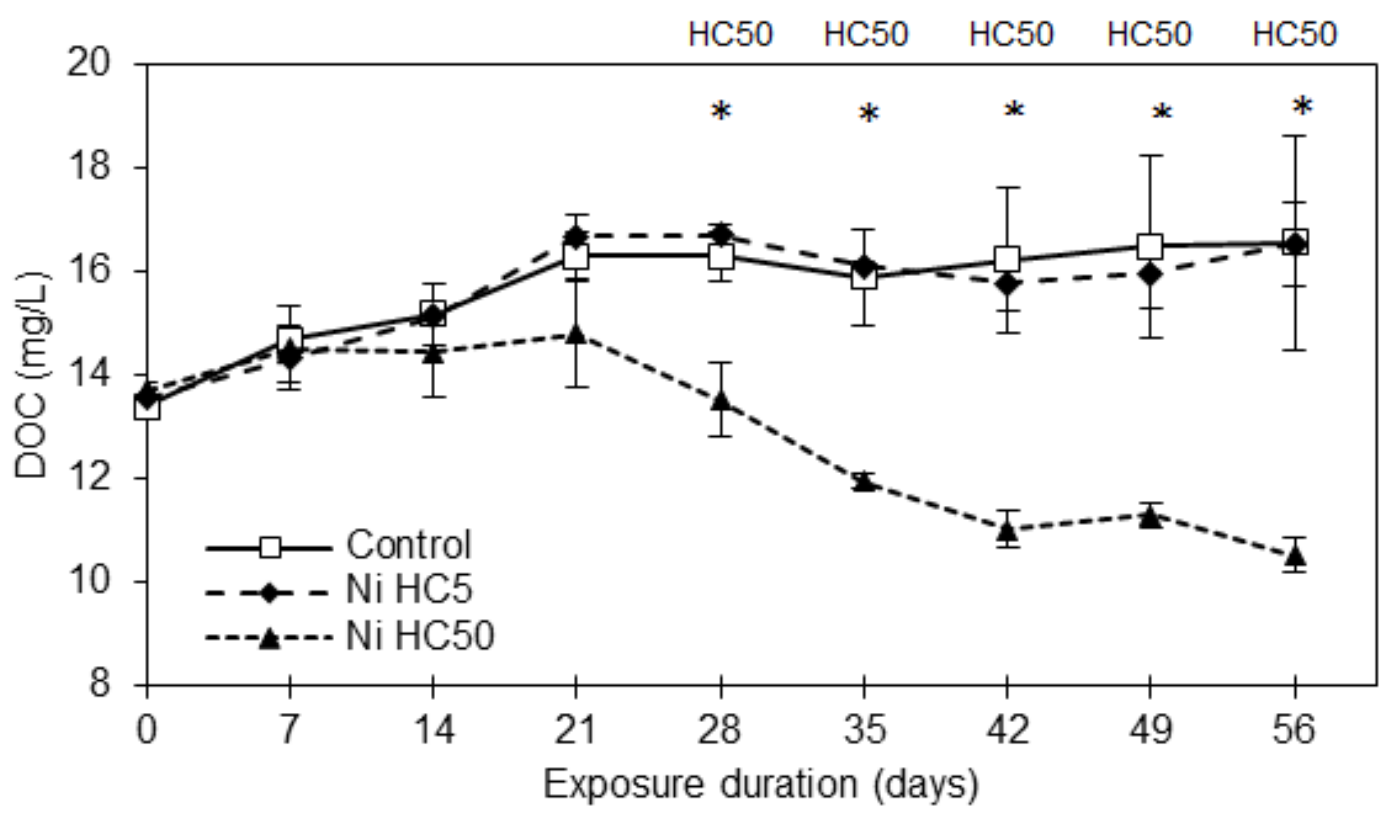

This article is protected by copyright. All rights reserved. 
Figure 3. Principal response curve (PRC) for the community effects analysis for phytoplankton (upper panel) and zooplankton (lower panel). The vertical axis represents the difference in community structure of the treatments compared to the control, expressed as the canonical regression coefficient ( $\mathrm{C}_{\mathrm{dt}}$; first PRC axis shown). The affinity of a species relative to the PRC is expressed as the species weight $\left(b_{k}\right.$; only species for which absolute $b_{k}>1$ are shown). F-statistics and p-value are those of the Monte-Carlo permutation test testing the significance of the first PRC axis. Asterisks indicate the occurrence of a significant difference in community structure from the control $(\mathrm{p}<0.05)$. Calculated lowest-observed-effect concentrations (LOEC) are plotted above the PRC for every sampling day. If nothing is indicated the LOEC was higher than the highest $\mathrm{Ni}$ treatment.
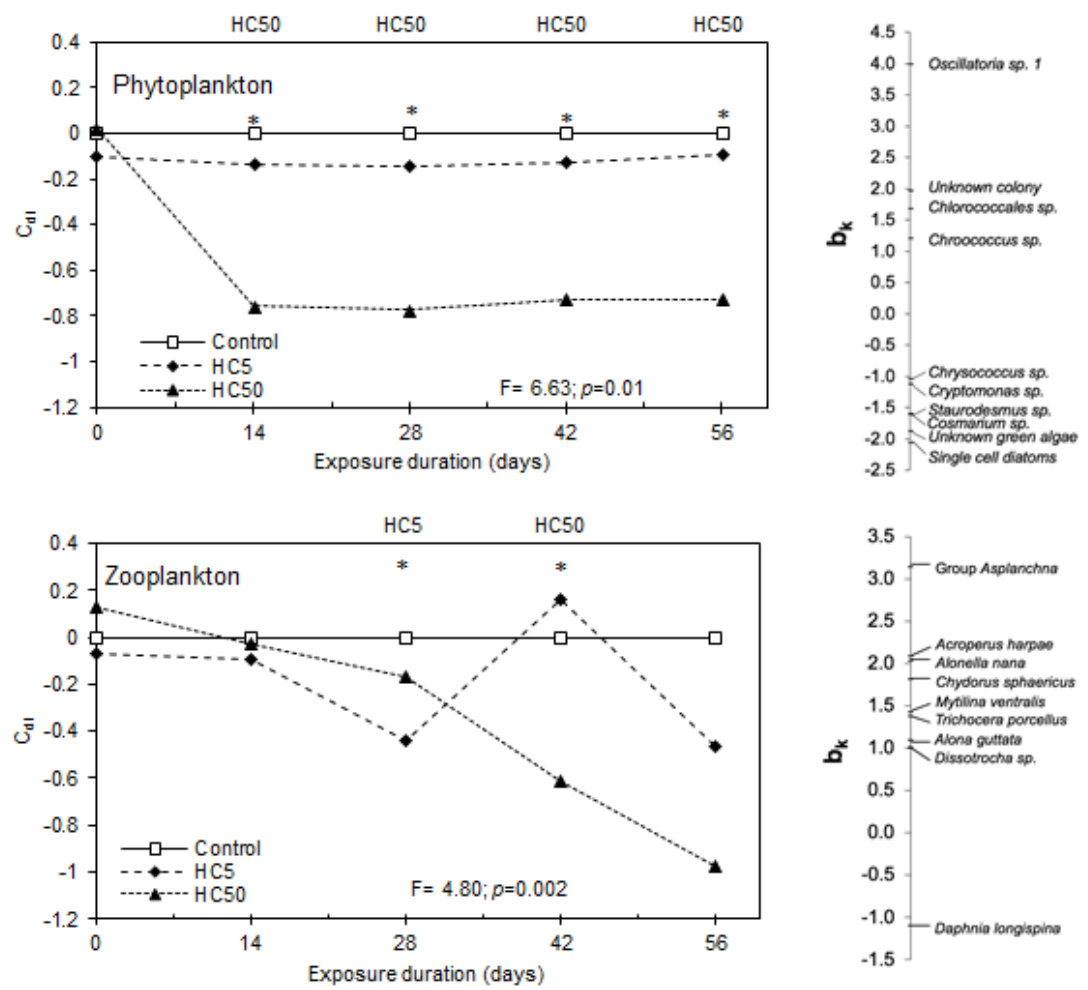

This article is protected by copyright. All rights reserved. 
Figure 4. Population dynamics of the cyanobacteria Oscillatoria sp. 1 (A) and the Single cell diatoms (B) (cell densities were $\ln (0.001 \mathrm{x}+1)$-transformed, with $\mathrm{x}$ the abundance of the algae); Asterisks indicate significant differences in abundances under Ni exposure relative to the control microcosms using the Williams test; $\mathrm{p}<0.05$. Calculated lowestobserved-effect concentrations (LOEC) for the species effect are plotted above panel A \& B. Abundance of Oscillatoria sp. 1 (C) and Single cell diatoms (D) relative to the total abundance of the phytoplankton. Error bars indicate standard errors on the average based on 4 (control) and 3 replicates (HC5, HC50).
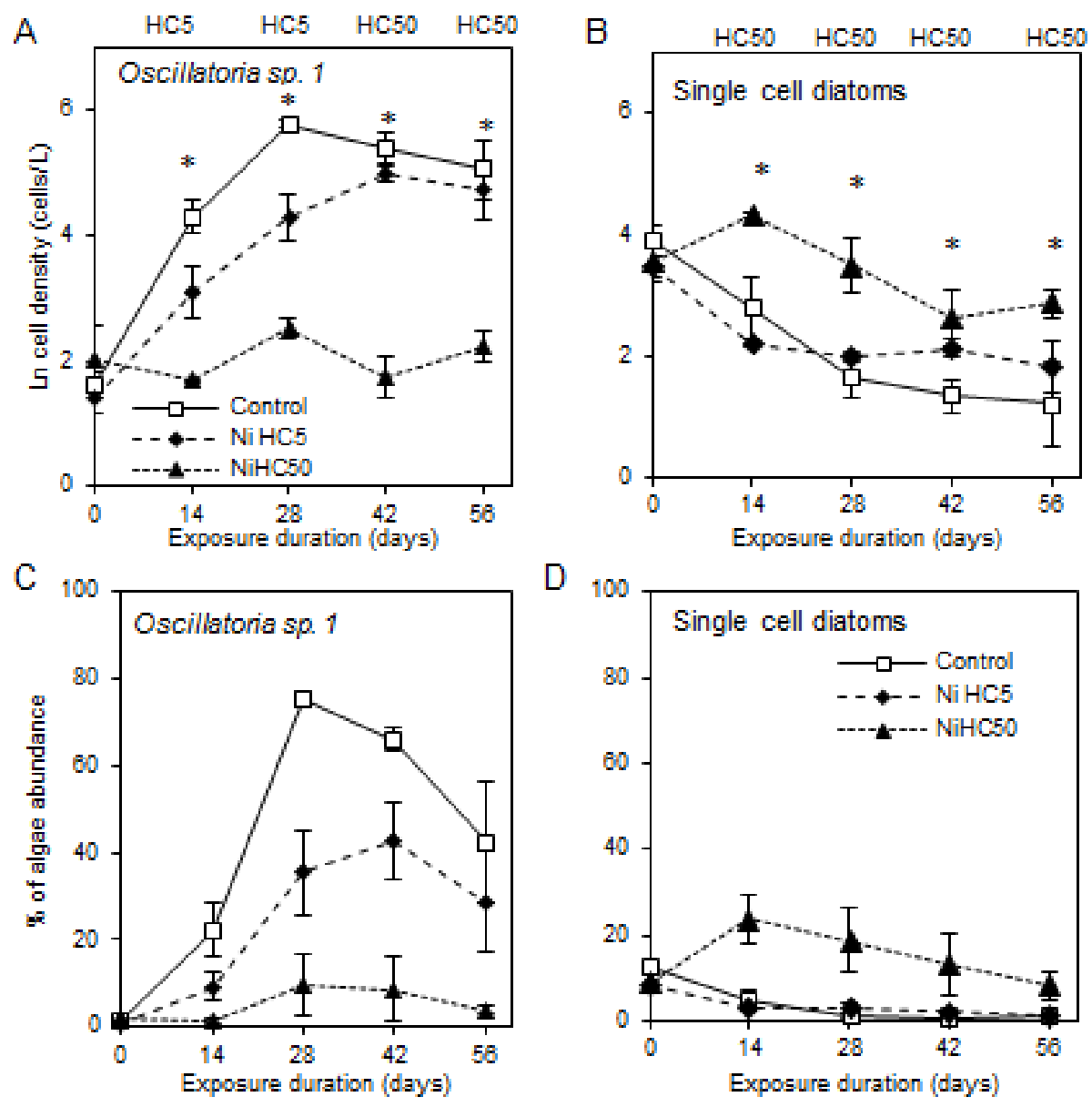

This article is protected by copyright. All rights reserved. 
Figure 5. Phytoplankton community dynamics (community structure endpoint) visualized as abundances of the different phytoplankton groups. Plotted abundances are ln-transformed $(\ln (0.001 \mathrm{x}+1))$ Error bars indicate standard errors on the average based on 4 (control) and 3 replicates (HC5, HC50). Asterisks indicate significant differences in abundances under $\mathrm{Ni}$ exposure relative to the control microcosms (Williams test; $\mathrm{p}<0.05$ ). Calculated lowest-observed-effect concentrations (LOEC) for the species effect are plotted above the figures (Williams test, $\mathrm{p}<0.05$ ). If nothing is indicated, the LOEC is higher than the highest Ni treatment.
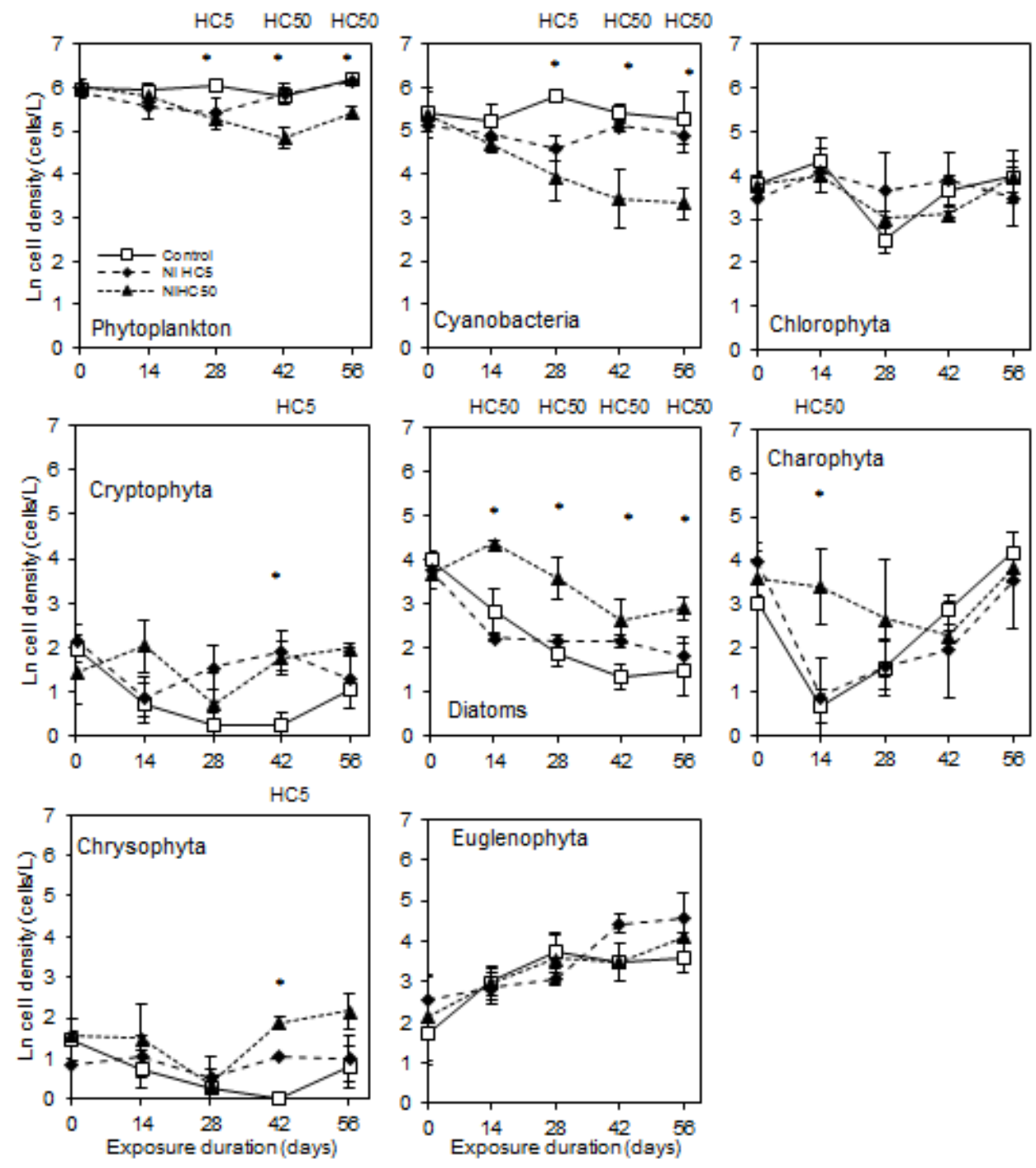

This article is protected by copyright. All rights reserved. 
Figure 6. Zooplankton community dynamics (community structure endpoint) visualized as abundances of the different zooplankton groups (rotifers (left upper panel), copepoda (right upper panel), cladocera (left lower panel), and ostracoda (right lower panel) ).

Plotted organism abundances are $\ln (0.81 \mathrm{x}+1)$-transformed, with $\mathrm{x}$ the abundance of the zooplankton group. Error bars indicate standard errors on the average based on 4 (control) and 3 replicates (HC5, HC50). Asterisks indicate significant differences in abundances under Ni exposure relative to the control microcosms (Williams test; $\mathrm{p}<0.05$ ). Calculated lowest-observed-effect concentrations (LOEC) are plotted above the PRC for every sampling day (Williams test, $\mathrm{p}<0.05$ ). If nothing is indicated, the LOEC was higher than the highest Ni treatment.
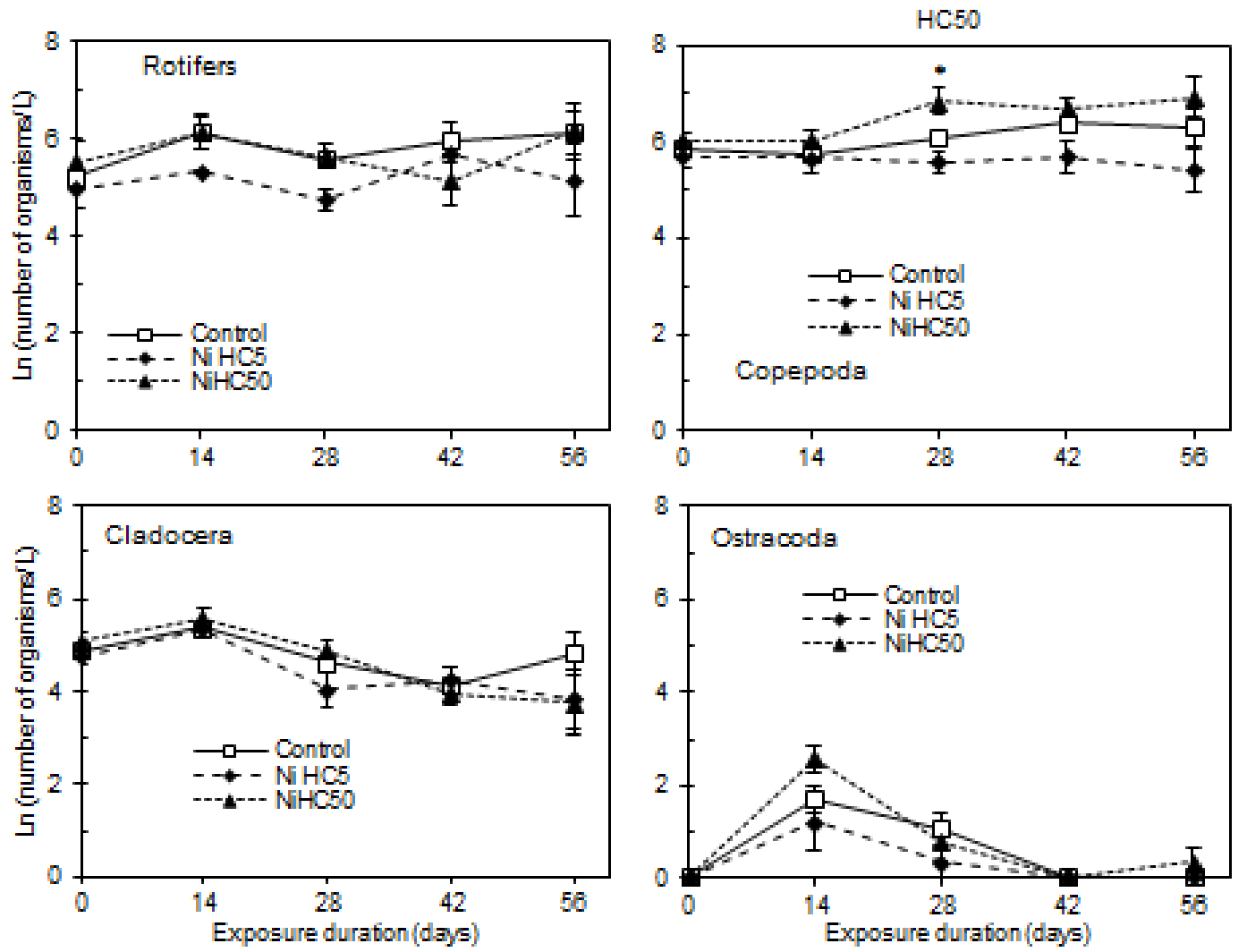

This article is protected by copyright. All rights reserved. 
Figure 7. Effect of Ni addition on indirect physico-chemical proxies for community respiration: $\Delta \mathrm{O}_{2}(\mathrm{mg} / \mathrm{L}$; upper panel), and $\Delta \mathrm{pH}$ (lower panel). Error bars indicate standard errors on the average based on 4 (control) and 3 replicates (HC5, HC50). Asterisks indicate significant differences in abundances under Ni exposure relative to the control microcosms (Williams test; $\mathrm{p}<0.05$ ). Calculated lowest-observed-effect concentrations (LOEC) for the physico-chemical proxies are plotted above the figures (Williams test, $\mathrm{p}<0.05$ ). If for a sampling day, no LOEC is plotted this indicates that the LOEC was higher than the highest Ni treatment.
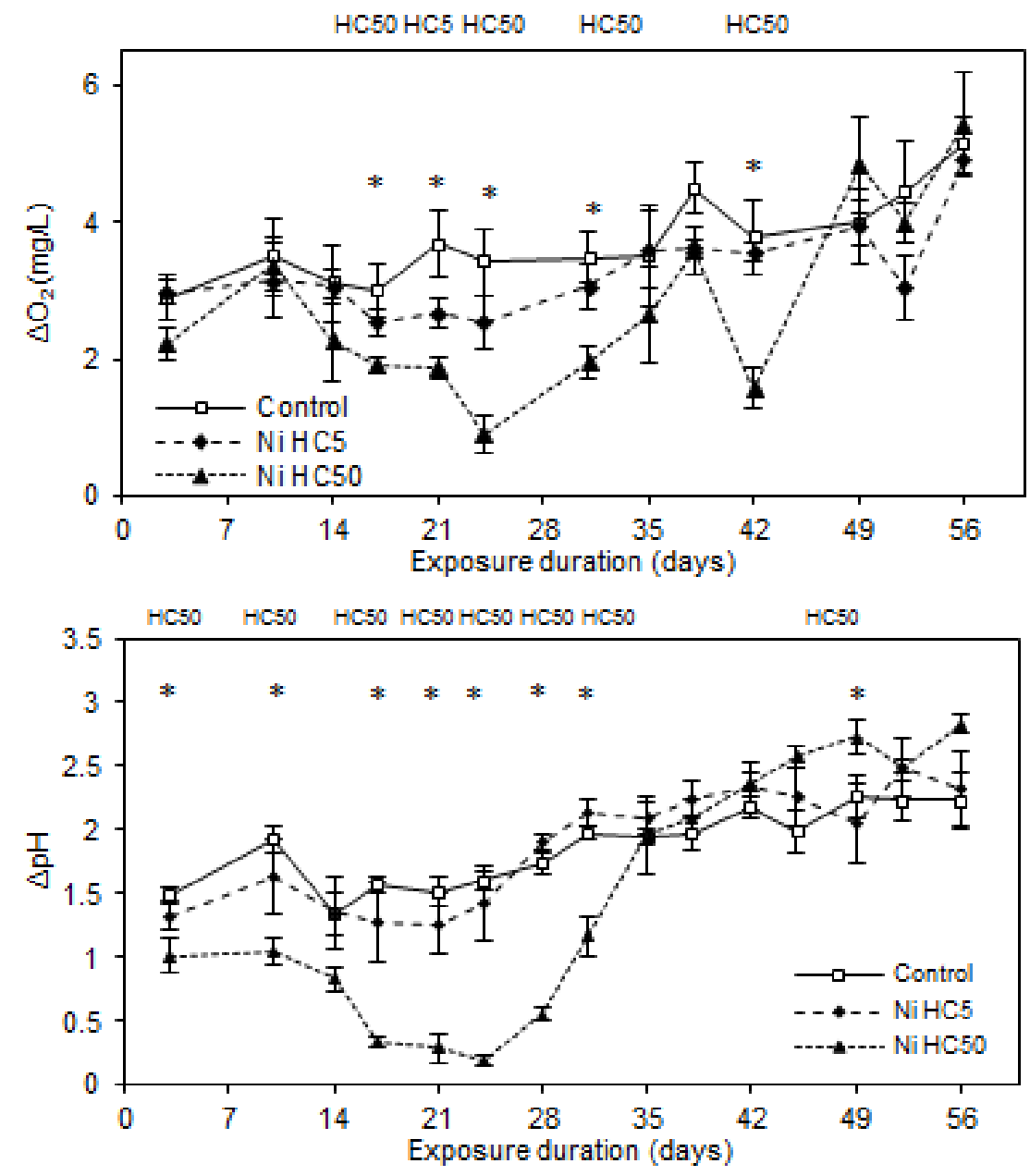

This article is protected by copyright. All rights reserved. 
Figure 8. Overview of hypothesized direct and indirect effects occurring in the microcosms after Ni application (at HC5 [upper panel] and HC50[lower panel]) on zooplankton and algae community structure and functioning. Bold arrows inside the rectangles indicate the direction of effect (regardless of it being direct or indirect) $(\uparrow=$ increase; $\downarrow=$ decrease). Only species showing effects belonging to class 3 and 4 are included. Higher taxa (cyanobacteria, and diatoms) that are printed bold were also classified in effect class 3 and 4; others did not show clear effects.
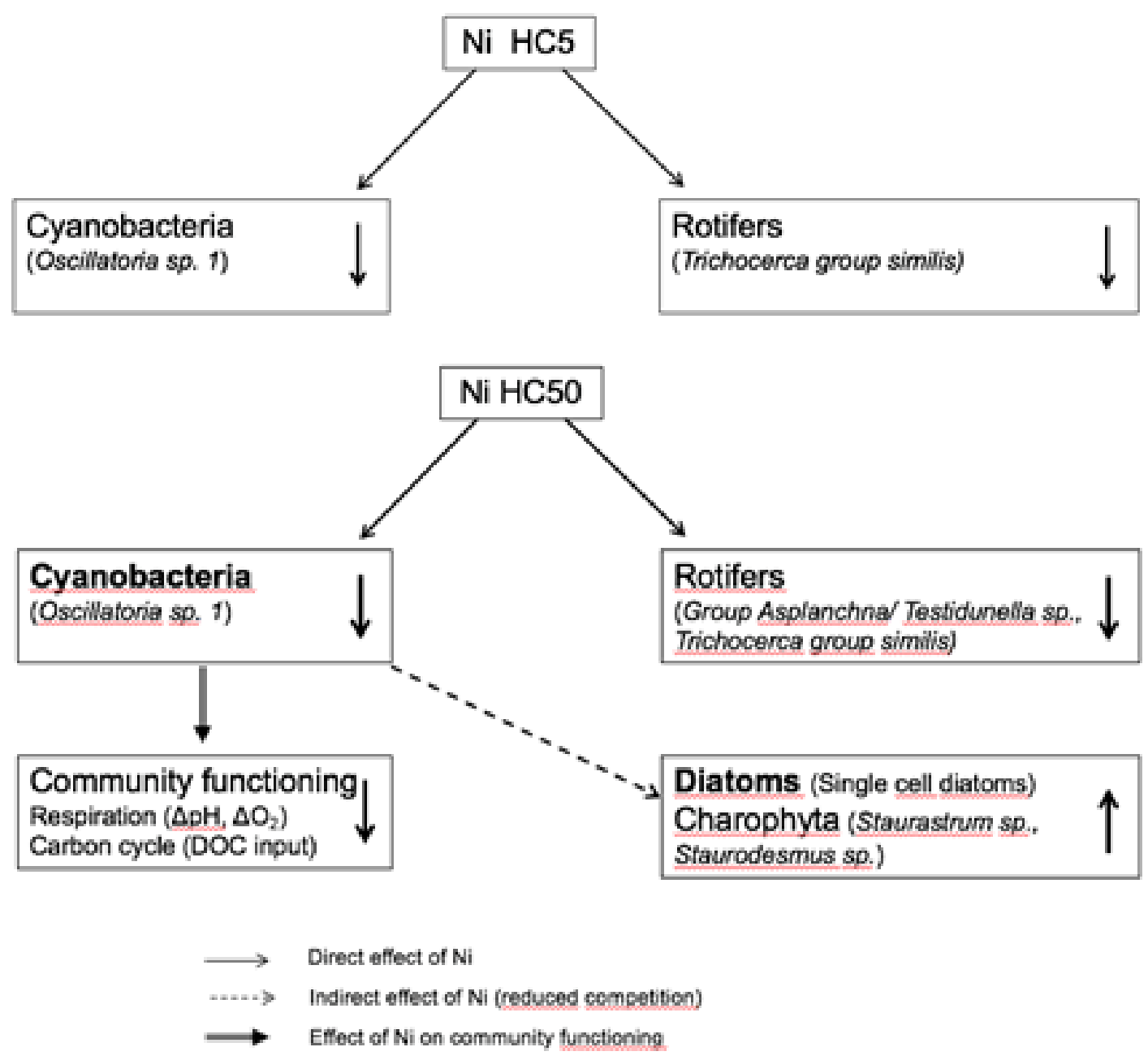

This article is protected by copyright. All rights reserved. 
Tables

Table 1. Overview of the average ${ }^{a}$ measured water chemistry variables of the microcosms the day before the start of the experiment and averages in the microcosms over the exposure period.

\begin{tabular}{|c|c|c|c|c|c|c|c|c|c|c|c|c|c|}
\hline & $\begin{array}{c}\text { Nomina } \\
1 \mathrm{Ni}\end{array}$ & $\begin{array}{c}\text { Dissolve } \\
\mathrm{d} \\
\mathrm{Ni}\end{array}$ & $\mathrm{pH}$ & DOC & $\mathrm{Ca}$ & $\mathrm{Mg}$ & $\mathrm{Na}$ & K & SO4 & $\mathrm{Cl}$ & DIC & $\mathrm{T}$ & $\begin{array}{c}\text { Dissolve } \\
\qquad \mathrm{d} \\
\mathrm{O}_{2}\end{array}$ \\
\hline & $(\mu \mathrm{g} / \mathrm{L})$ & $(\mu \mathrm{g} / \mathrm{L})$ & & $\begin{array}{c}(\mathrm{mg} / \mathrm{L} \\
)\end{array}$ & $\begin{array}{c}(\mathrm{mg} / \mathrm{L} \\
)\end{array}$ & $(\mathrm{mg} / \mathrm{L})$ & $(\mathrm{mg} / \mathrm{L})$ & $(\mathrm{mg} / \mathrm{L})$ & $(\mathrm{mg} / \mathrm{L})$ & $(\mathrm{mg} / \mathrm{L})$ & $(\mathrm{mg} / \mathrm{L})$ & $\left({ }^{\circ} \mathrm{C}\right)$ & $(\mathrm{mg} / \mathrm{L})$ \\
\hline $\begin{array}{c}\text { Test } \\
\text { initiation } \\
\mathrm{b}\end{array}$ & NA & $<\mathrm{QL}^{\mathrm{c}}$ & $\begin{array}{c}8.1 \pm 0 . \\
3\end{array}$ & 14 & $12 \pm 1$ & $\begin{array}{c}1.6 \pm 0 \\
1\end{array}$ & $\begin{array}{c}4.7 \pm 0 \\
3\end{array}$ & $\begin{array}{c}0.3 \pm 0 \\
1\end{array}$ & $9.8 \pm 2$ & $\begin{array}{c}7.8 \pm 0 . \\
5\end{array}$ & $\begin{array}{c}4.0 \pm 0 . \\
3\end{array}$ & $\begin{array}{c}17 \pm \\
0\end{array}$ & $11 \pm 1$ \\
\hline Control & 0 & $<\mathrm{QL}^{\mathrm{c}}$ & $\begin{array}{c}8.3 \pm 0 \\
9\end{array}$ & $16 \pm 2$ & $14 \pm 2$ & $\begin{array}{c}1.9 \pm 0 \\
1\end{array}$ & $\begin{array}{c}5.3 \pm 0 . \\
3\end{array}$ & $\begin{array}{c}0.2 \pm 0 \\
1\end{array}$ & $\begin{array}{c}6.0 \pm 1 \\
2\end{array}$ & $\begin{array}{c}7.3 \pm 1 . \\
1\end{array}$ & $\begin{array}{c}5.9 \pm 0 \\
3\end{array}$ & $\begin{array}{c}17 \pm \\
1\end{array}$ & $10 \pm 2$ \\
\hline HC5 & 24 & $23 \pm 3$ & $\begin{array}{c}8.2 \pm 1 \\
0\end{array}$ & $16 \pm 1$ & $18 \pm 6$ & $\begin{array}{c}2.2 \pm 0 \\
3\end{array}$ & $\begin{array}{c}5.2 \pm 0 . \\
7\end{array}$ & $\begin{array}{c}0.4 \pm 0 \\
1\end{array}$ & $\begin{array}{c}6.8 \pm 1 \\
4\end{array}$ & $\begin{array}{c}7.2 \pm 1 . \\
5\end{array}$ & $\begin{array}{c}6.2 \pm 1 \\
0\end{array}$ & $\begin{array}{c}17 \pm \\
0\end{array}$ & $10 \pm 2$ \\
\hline HC50 & 97 & $93 \pm 14$ & $\begin{array}{c}7.9 \pm 1 . \\
0\end{array}$ & $13 \pm 2$ & $18 \pm 6$ & $\begin{array}{c}2.2 \pm 0 \\
4\end{array}$ & $\begin{array}{c}5.2 \pm 0 . \\
7\end{array}$ & $\begin{array}{c}0.4 \pm 0 . \\
1\end{array}$ & $\begin{array}{c}7.3 \pm 2 . \\
8\end{array}$ & $\begin{array}{c}7.9 \pm 0 \\
4\end{array}$ & $\begin{array}{c}5.4 \pm 1 \\
0\end{array}$ & $\begin{array}{c}17 \pm \\
0\end{array}$ & $10 \pm 2$ \\
\hline
\end{tabular}

${ }^{\mathrm{a}}$ Average values \pm standard deviations are reported

${ }^{\mathrm{b}}$ Measured in the microcosms one day prior to test initiation (before first Ni addition; average of all 10 microcosms). This physico-chemistry was used to determine the bioavailable HC5 and HC50 to be applied to the test-systems using the bioavailability normalisation and SSD-derivation of Nys et al. (2016).

${ }^{\mathrm{c}}$ Measured dissolved Ni concentrations before test initiation and in the control microcosms were lower than the quantification limit $(\mathrm{QL})$ of the ICP-OES (QL=4 $\mu \mathrm{g}$ $\mathrm{Ni} / \mathrm{L})$.

This article is protected by copyright. All rights reserved. 
DOC $=$ Dissolved Organic Carbon; DIC = Dissolved Inorganic Carbon, $\mathrm{T}=$ temperature;

HC5 $=$ concentration hazardous for $5 \%$ of the species; HC50 = concentration hazardous for $50 \%$ of the species

Table 2. Lowest observed effect concentrations ${ }^{\mathrm{a}}$ (LOEC) per sampling day for the community structure-effect (principal response curves and phytoplankton groups ${ }^{\mathrm{b}}$ ), species-effects $^{\mathrm{b}}$, Minimal Detectable Difference (MDD) and effect classification ${ }^{\mathrm{c}}$ for both treatments class for the phytoplankton.

\begin{tabular}{|c|c|c|c|c|c|c|c|c|c|}
\hline $\begin{array}{l}\text { Phytoplankton } \\
\text { group }\end{array}$ & Endpointspecies & $\begin{array}{c}\text { LOE } \\
\text { C } \\
\text { Day } \\
0\end{array}$ & $\begin{array}{c}\text { LOEC } \\
\text { Day } \\
14\end{array}$ & $\begin{array}{l}\text { LOEC } \\
\text { Day } \\
28\end{array}$ & $\begin{array}{c}\text { LOEC } \\
\text { Day } \\
42\end{array}$ & $\begin{array}{c}\text { LOEC } \\
\text { Day } \\
56\end{array}$ & $\begin{array}{c}\text { MDD } \\
\text { Clas } \\
\mathrm{s}^{\mathrm{a}}\end{array}$ & $\begin{array}{c}\text { Effe } \\
\text { ct } \\
\text { clas } \\
\text { S at } \\
\text { HC5 }\end{array}$ & $\begin{array}{c}\text { Effe } \\
\text { ct } \\
\text { clas } \\
\text { s at } \\
\text { HC5 } \\
0\end{array}$ \\
\hline \multirow[t]{3}{*}{ Phytoplankton } & Principal response curve & & HC50 & HC50 & HC50 & HC50 & - & 1 & 4 \\
\hline & Total abundance & & & HC5 $\downarrow$ & $\begin{array}{l}\mathrm{HC} 50 \\
\downarrow\end{array}$ & $\begin{array}{l}\mathrm{HC} 50 \\
\downarrow\end{array}$ & 1 & $2 \mathrm{a} \downarrow$ & $4 \downarrow$ \\
\hline & Unknown colony & & $\begin{array}{c}\mathrm{HC} 50 \\
\downarrow\end{array}$ & & $\begin{array}{c}\mathrm{HC} 50 \\
\downarrow\end{array}$ & & 2 & 1 & $2 \mathrm{a} \downarrow$ \\
\hline \multirow[t]{5}{*}{ Cyanobacteria } & & & & HC5 $\downarrow$ & $\begin{array}{c}\mathrm{HC} 50 \\
\downarrow\end{array}$ & $\begin{array}{c}\mathrm{HC} 50 \\
\downarrow\end{array}$ & 1 & $2 \mathrm{a} \downarrow$ & $4 \downarrow$ \\
\hline & Oscillatoria 1 & & $\mathrm{HC} 5 \downarrow$ & HC5 $\downarrow$ & $\begin{array}{c}\mathrm{HC} 50 \\
\downarrow\end{array}$ & $\begin{array}{c}\mathrm{HC} 50 \\
\downarrow\end{array}$ & 1 & $3 \downarrow$ & $4 \downarrow$ \\
\hline & Aphanocapsa & & & & $\begin{array}{c}\mathrm{HC} 50 \\
\uparrow\end{array}$ & & 2 & 1 & $2 \mathrm{a} \uparrow$ \\
\hline & Pseudanabaenoideae & & & $\mathrm{HC} 5 \uparrow$ & & & 2 & $2 \mathrm{a} \downarrow$ & $2 \mathrm{a} \downarrow$ \\
\hline & Chroococcus & & & & HC5 $\uparrow$ & HC5 $\downarrow$ & 2 & $\begin{array}{l}2 \mathrm{~b} \\
\uparrow \downarrow\end{array}$ & $\begin{array}{l}2 \mathrm{~b} \\
\uparrow \downarrow\end{array}$ \\
\hline Diatoms & & & HC50 & HC50 & HC50 & HC50 & 2 & 1 & $4 \uparrow$ \\
\hline
\end{tabular}

This article is protected by copyright. All rights reserved. 


\begin{tabular}{|c|c|c|c|c|c|c|c|c|c|}
\hline & & & $\uparrow$ & $\uparrow$ & $\uparrow$ & $\uparrow$ & & & \\
\hline & Single cell Diatoms & & $\begin{array}{c}\mathrm{HC} 50 \\
\uparrow\end{array}$ & $\begin{array}{c}\mathrm{HC} 50 \\
\uparrow\end{array}$ & $\begin{array}{c}\mathrm{HC} 50 \\
\uparrow\end{array}$ & $\begin{array}{c}\mathrm{HC} 50 \\
\uparrow\end{array}$ & 2 & 1 & $4 \uparrow$ \\
\hline \multirow[t]{7}{*}{ Chlorophyceae } & & & & & & & 1 & 1 & 1 \\
\hline & Chlorococcales & & & & $\begin{array}{c}\mathrm{HC} 50 \\
\downarrow\end{array}$ & & 2 & 1 & $2 \mathrm{a} \downarrow$ \\
\hline & Gonium & & $\begin{array}{c}\mathrm{HC} 50 \\
\uparrow\end{array}$ & & & NR & 2 & 1 & $2 \mathrm{a} \uparrow$ \\
\hline & Oocystis & & & & $\underset{\uparrow}{\mathrm{HC} 50}$ & & 2 & 1 & $2 \mathrm{a} \uparrow$ \\
\hline & Ankistrodesmus & & $\underset{\uparrow}{\mathrm{HC} 50}$ & & NR & NR & 2 & 1 & $2 \mathrm{a} \uparrow$ \\
\hline & Haematococcus & & & $\begin{array}{c}\mathrm{HC} 50 \\
\uparrow\end{array}$ & & & 2 & 1 & $2 \mathrm{a} \uparrow$ \\
\hline & $\begin{array}{l}\text { Unknown green algae } \\
\text { colony }\end{array}$ & NR & NR & $\begin{array}{c}\mathrm{HC} 50 \\
\uparrow\end{array}$ & & $\begin{array}{c}\mathrm{HC} 50 \\
\uparrow\end{array}$ & 2 & 1 & $2 \mathrm{~b} \uparrow$ \\
\hline \multirow[t]{5}{*}{ Charophyta } & & & $\begin{array}{c}\mathrm{HC} 50 \\
\uparrow\end{array}$ & & & & 2 & 1 & $2 a \uparrow$ \\
\hline & Staurodesmus & & $\begin{array}{c}\mathrm{HC} 50 \\
\uparrow\end{array}$ & $\begin{array}{c}\mathrm{HC} 50 \\
\uparrow\end{array}$ & & $\begin{array}{c}\mathrm{HC} 50 \\
\uparrow\end{array}$ & 2 & 1 & $2 b \uparrow$ \\
\hline & Cosmarium & & $\begin{array}{c}\mathrm{HC} 50 \\
\uparrow\end{array}$ & & & $\begin{array}{c}\mathrm{HC} 50 \\
\uparrow\end{array}$ & 2 & 1 & $2 \mathrm{~b} \uparrow$ \\
\hline & Staurastrum & & $\begin{array}{c}\mathrm{HC} 50 \\
\uparrow\end{array}$ & $\begin{array}{c}\mathrm{HC} 50 \\
\uparrow\end{array}$ & & & 2 & 1 & $3 \uparrow$ \\
\hline & Mougeotia & $\mathrm{NR}$ & $\begin{array}{c}\mathrm{HC} 50 \\
\uparrow\end{array}$ & & & & 2 & 1 & $2 a \uparrow$ \\
\hline Cryptophycaea & & & & & $\mathrm{HC} 5 \uparrow$ & & 2 & $2 \mathrm{a} \uparrow$ & $2 \mathrm{a} \uparrow$ \\
\hline
\end{tabular}

This article is protected by copyright. All rights reserved. 


\begin{tabular}{|c|c|c|c|c|c|c|c|c|c|}
\hline & Rhodomonas & $N R$ & NR & NR & & HC50 & 2 & 1 & $2 \mathrm{~b} \uparrow$ \\
\hline & Cryptomonas & & & & $\mathrm{HC} 50$ & & 2 & 1 & $2 a \uparrow$ \\
\hline \multirow[t]{2}{*}{ Chrysophyceae } & & & & & $\mathrm{HC} 5 \uparrow$ & & 2 & $2 \mathrm{a} \uparrow$ & $2 \mathrm{a} \uparrow$ \\
\hline & Chrysococcus & & & & $\mathrm{HC} 5 \uparrow$ & & 2 & $2 a \uparrow$ & $2 a \uparrow$ \\
\hline \multirow{2}{*}{ Euglenoida } & & & & & & & 1 & 1 & 1 \\
\hline & Euglenida 2 & & & & & $\underset{\uparrow}{\mathrm{HC} 50}$ & 2 & 1 & $2 \mathrm{~b} \uparrow$ \\
\hline \multicolumn{2}{|c|}{$\begin{array}{l}\text { Number of taxa affected at HC5 } \\
\text { (phytoplankton groups/species) }\end{array}$} & $0 / 0$ & $0 / 1$ & $1 / 2$ & $2 / 2$ & $0 / 1$ & & & \\
\hline \multicolumn{2}{|c|}{$\begin{array}{l}\text { Number of taxa affected at HC50 } \\
\text { (phytoplankton groups/species) }\end{array}$} & $0 / 0$ & $2 / 8$ & $2 / 7$ & $4 / 9$ & $2 / 8$ & & & \\
\hline
\end{tabular}

${ }^{\mathrm{a}} \mathrm{HC} 5=\mathrm{LOEC}$ is equal to the $\mathrm{HC} 5$ treatment (i.e. significant effects at the $\mathrm{HC} 5$ treatment observed); $\mathrm{HC} 50=$ LOEC is equal to the HC50-treatment; if nothing is printed, the LOEC is higher than the highest tested concentration. LOECs per sampling date were determined using the Williams test $(p<0.05)$.

${ }^{\mathrm{b}}$ LOEC calculations were done based on total abundances per phytoplankton group/species. Only phytoplankton groups and species of MDD class 1 and 2 are listed. If significant effects were observed, the direction of effect was indicated as follows: $\uparrow$ increase in abundance; $\downarrow$ decrease in abundance; $\uparrow \downarrow$ both increase and decrease in abundance observed on different sampling days

${ }^{\mathrm{c}}$ Effect classification was defined as follows: $1=$ no effect; $2 \mathrm{a}=$ temporary effect (only on individual sampling days, but excluding the last sampling day); $2 \mathrm{~b}=$ effect on the last sampling day; $3=$ clear effect with full recovery; 4 = clear effect without full recovery,

$N R=$ species not recorded on sampling day

This article is protected by copyright. All rights reserved. 
Table 3. Lowest observed effect concentrations ${ }^{\mathrm{a}}$ (LOEC) per sampling day for the community structure-effect (principal response curves and zooplankton groups ${ }^{\mathrm{b}}$ ), specieseffects $^{\mathrm{b}}$, Minimal Detectable Difference (MDD) class and effect classification ${ }^{\mathrm{c}}$ for both treatments for the zooplankton.

\begin{tabular}{|c|c|c|c|c|c|c|c|c|c|}
\hline Zooplankton group & Endpoint/ species & $\begin{array}{l}\text { LOEC } \\
\text { Day } 0\end{array}$ & $\begin{array}{l}\text { LOEC } \\
\text { Day } 14\end{array}$ & $\begin{array}{l}\text { LOEC } \\
\text { Day } 28\end{array}$ & $\begin{array}{l}\text { LOEC } \\
\text { Day } 42\end{array}$ & $\begin{array}{l}\text { LOEC } \\
\text { Day } 56\end{array}$ & $\begin{array}{l}\text { MDD } \\
\text { class }^{a}\end{array}$ & $\begin{array}{c}\text { Effect } \\
\text { class at } \\
\text { HC5 }\end{array}$ & $\begin{array}{c}\text { Effect } \\
\text { class at } \\
\text { HC50 }\end{array}$ \\
\hline \multirow[t]{2}{*}{ Zooplankton } & Principal response curve & & & HC5 & HC50 & & - & $2 a$ & 3 \\
\hline & Total abundance & & & $\mathrm{HC} 50 \uparrow$ & & & 1 & 1 & $2 \mathrm{a} \uparrow$ \\
\hline \multirow[t]{3}{*}{ Rotifers } & & & & & & & 1 & 1 & 1 \\
\hline & Lecane group luna & & & & & & 1 & 1 & 1 \\
\hline & Lecane group lunaris & & & & HC5 $\downarrow$ & & 1 & $2 \mathrm{a} \downarrow$ & $2 \mathrm{a} \downarrow$ \\
\hline & Lepadella patella & & & & & & 1 & 1 & 1 \\
\hline & Group Asplanchna/Testidunela sp. & & & & HC50 $\downarrow$ & HC50 $\downarrow$ & 2 & 1 & $4 \downarrow$ \\
\hline & Trichocerca group similis & & HC5 $\downarrow$ & HC5 $\downarrow$ & & & 2 & $3 \downarrow$ & $3 \downarrow$ \\
\hline & Ascomorpha saltans & NR & & & & HC5 $\downarrow$ & 2 & $2 \mathrm{~b} \downarrow$ & $2 \mathrm{~b} \downarrow$ \\
\hline & Cephalodella gibba & & & $\mathrm{HC} 5 \uparrow$ & & & 2 & $2 \mathrm{a} \uparrow$ & $2 a \uparrow$ \\
\hline & Mytilina ventralis & & & & HC50 & & 2 & 1 & $2 \mathrm{a} \downarrow$ \\
\hline Cladocera & & & & & & & 1 & 1 & 1 \\
\hline & Simocephalus vetulus & & $\mathrm{HC} 5 \uparrow$ & & & HC50 $\downarrow$ & 2 & $2 a \uparrow$ & $2 \mathrm{~b} \downarrow$ \\
\hline & Chydorus sphaericus & & & & & $\mathrm{HC} 50 \downarrow$ & 2 & 1 & $2 \mathrm{~b} \downarrow$ \\
\hline & Alonella nana & & & HC5 $\downarrow$ & & & 2 & $2 \mathrm{a} \downarrow$ & $2 \mathrm{a} \downarrow$ \\
\hline
\end{tabular}

This article is protected by copyright. All rights reserved. 


\begin{tabular}{|c|c|c|c|c|c|c|c|c|c|}
\hline & Alona quadrangularis & & & & HC5 $\uparrow$ & & 2 & $2 a \uparrow$ & $2 a \uparrow$ \\
\hline & Alona rectangula & & & HC5 $\downarrow$ & & & 2 & $2 \mathrm{a} \downarrow$ & $2 a \downarrow$ \\
\hline & Alona guttata & NR & & & & HC5 $\downarrow$ & 2 & $2 b \downarrow$ & $2 \mathrm{~b} \downarrow$ \\
\hline & Acroperus harpae & & & & & HC5 $\downarrow$ & 2 & $2 \mathrm{~b} \downarrow$ & $2 \mathrm{~b} \downarrow$ \\
\hline & Graptoleberis testudinaria & & NR & & & HC50 $\downarrow$ & 2 & 1 & $2 \mathrm{~b} \downarrow$ \\
\hline Copepoda & & & & $\mathrm{HC} 50 \uparrow$ & & & 1 & 1 & $2 a \uparrow$ \\
\hline & Cyclopoida & & & & & & 1 & 1 & 1 \\
\hline & Nauplius & & & HC50 $\uparrow$ & & & 1 & 1 & $2 a \uparrow$ \\
\hline \multicolumn{2}{|c|}{$\begin{array}{l}\text { Number of taxa affected at HC5 } \\
\text { (zooplankton groups/species) }\end{array}$} & $0 / 0$ & $0 / 2$ & $0 / 4$ & $0 / 2$ & $0 / 3$ & & & \\
\hline \multicolumn{2}{|c|}{ Number of taxa affected at HC50 } & & & & & & & & \\
\hline \multicolumn{2}{|c|}{ (zooplankton groups/species) } & & & & & & & & \\
\hline
\end{tabular}

${ }^{\mathrm{a}} \mathrm{HC} 5=\mathrm{LOEC}$ is equal to the HC5 treatment (i.e. significant effects at the HC5 treatment observed); HC50= LOEC is equal to the HC50-treatment; if nothing is printed, the LOEC is higher than the highest tested concentration. LOECs per sampling date were determined using the Williams test $(p<0.05)$.

${ }^{\mathrm{b}}$ LOEC calculations were done based on total abundances per phytoplankton group/species. Only species and groups of MDD class 1 and 2 are listed. If significant effects were observed, the direction of effect was indicated as follows: $\uparrow$ increase in abundance; $\downarrow$ decrease in abundance

${ }^{\mathrm{c}}$ Effect classification was defined as follows: $1=$ no effect; $2 \mathrm{a}=$ temporary effect (only on individual sampling days, but excluding the last sampling day); $2 \mathrm{~b}=$ effect on the last sampling day; $3=$ clear effect with full recovery; 4 = clear effect without full recovery

$\mathrm{NR}=$ species not recorded on sampling day

This article is protected by copyright. All rights reserved. 
Table 4. Lowest observed effect concentrations ${ }^{\mathrm{a}}$ (LOEC) per sampling day for the community functioning endpoints ${ }^{\mathrm{b}}$, Minimal Detectable Difference (MDD) class and effect classification ${ }^{\mathrm{c}}$ for both treatments

\begin{tabular}{|c|c|c|c|c|c|c|c|c|c|c|c|c|c|c|c|c|c|c|c|}
\hline & \multicolumn{16}{|c|}{ Days after first Ni addition } & \multirow{2}{*}{$\begin{array}{c}\text { MD } \\
\text { D } \\
\text { Cla } \\
\text { ss }\end{array}$} & \multirow{2}{*}{$\begin{array}{c}\text { Effe } \\
\text { ct } \\
\text { clas } \\
\mathrm{s} \text { at } \\
\text { HC5 }\end{array}$} & \multirow{2}{*}{$\begin{array}{l}\text { Effe } \\
\text { ct } \\
\text { clas } \\
\text { s at } \\
\text { HC5 }\end{array}$} \\
\hline & 3 & 7 & 10 & $\begin{array}{l}1 \\
4\end{array}$ & 17 & 21 & 24 & 28 & 31 & 35 & $\begin{array}{l}3 \\
8\end{array}$ & 42 & 45 & 49 & $\begin{array}{l}5 \\
2\end{array}$ & 56 & & & \\
\hline $\begin{array}{l}\Delta O \\
2\end{array}$ & & - & & & $\begin{array}{l}\text { HC5 } \\
0 \downarrow^{b}\end{array}$ & $\begin{array}{c}\text { HC5 } \\
\downarrow\end{array}$ & $\begin{array}{c}\text { HC5 } \\
0 \downarrow\end{array}$ & - & $\begin{array}{c}\text { HC5 } \\
0 \downarrow\end{array}$ & & & $\begin{array}{c}\text { HC5 } \\
0 \downarrow\end{array}$ & - & & & & 1 & $2 \downarrow$ & $3 \downarrow$ \\
\hline $\begin{array}{l}\Delta p \\
H\end{array}$ & $\begin{array}{c}\text { HC5 } \\
0 \downarrow \downarrow\end{array}$ & - & $\begin{array}{c}\text { HC5 } \\
0 \downarrow\end{array}$ & & $\begin{array}{c}\text { HC5 } \\
0 \downarrow\end{array}$ & $\begin{array}{c}\text { HC5 } \\
0 \downarrow\end{array}$ & $\begin{array}{c}\text { HC5 } \\
0 \downarrow\end{array}$ & $\begin{array}{c}\text { HC5 } \\
0 \downarrow\end{array}$ & $\begin{array}{c}\text { HC5 } \\
0 \downarrow\end{array}$ & & & & $\begin{array}{c}\text { HC5 } \\
0 \uparrow\end{array}$ & & & & 1 & 1 & $3 \downarrow$ \\
\hline $\begin{array}{l}\text { DO } \\
\text { C }\end{array}$ & - & & - & & - & & - & $\begin{array}{c}\text { HC5 } \\
0 \downarrow\end{array}$ & - & $\begin{array}{c}\text { HC5 } \\
0 \downarrow\end{array}$ & - & $\begin{array}{c}\text { HC5 } \\
0 \downarrow\end{array}$ & - & $\begin{array}{c}\text { HC5 } \\
0 \downarrow\end{array}$ & - & $\begin{array}{c}\text { HC5 } \\
0 \downarrow\end{array}$ & 1 & 1 & $4 \downarrow$ \\
\hline
\end{tabular}

\footnotetext{
${ }^{\mathrm{a}} \mathrm{HC} 5=\mathrm{LOEC}$ is equal to the HC5 treatment (i.e. significant effects at the HC5 treatment observed); HC50= LOEC is equal to the HC50-treatment; if nothing is printed, the LOEC is higher than the highest tested concentration. "-" means that endpoint was not measured on particular day. LOECs per sampling date were determined using the Williams test $(p<0.05)$. If significant effects were observed, the direction of effect was indicated as follows: $\uparrow$ increase in functional parameter; $\downarrow$ decrease in functional parameter

${ }^{\mathrm{b}} \Delta \mathrm{O}_{2}$ and $\triangle \mathrm{pH}$ are proxies for community respiration, $\mathrm{DOC}$ (dissolved organic carbon) is used as a proxy for the microbial loop

${ }^{\mathrm{c}}$ Effect classification was defined as follows: $1=$ no effect; $2 a=$ temporary effect (only on individual sampling days, but excluding the last sampling day); $2 \mathrm{~b}=$ effect on the last sampling day; $3=$ clear effect with full recovery; 4 = clear effect without full recovery
}

This article is protected by copyright. All rights reserved. 